\title{
Glioblastoma-targeted CD4+ CAR T cells mediate superior antitumor activity
}

\author{
Dongrui Wang, ${ }^{1,2}$ Brenda Aguilar, ${ }^{1}$ Renate Starr, ${ }^{1}$ Darya Alizadeh, ${ }^{1}$ Alfonso Brito, ${ }^{1}$ Aniee Sarkissian, \\ Julie R. Ostberg, ${ }^{1}$ Stephen J. Forman, ${ }^{1}$ and Christine E. Brown ${ }^{1}$ \\ 'Department of Hematology and Hematopoietic Cell Transplantation, T Cell Therapeutics Research Laboratory, and \\ ${ }^{2}$ Irell and Manella Graduate School of Biological Sciences, City of Hope (COH) Beckman Research Institute and Medical \\ Center, Duarte, California, USA.
}

\begin{abstract}
Chimeric antigen receptor-modified (CAR-modified) T cells have shown promising therapeutic effects for hematological malignancies, yet limited and inconsistent efficacy against solid tumors. The refinement of CAR therapy requires an understanding of the optimal characteristics of the cellular products, including the appropriate composition of $\mathrm{CD4}^{+}$and $\mathrm{CD8} 8^{+}$subsets. Here, we investigated the differential antitumor effect of CD4+ and CD8+ CAR T cells targeting glioblastomaassociated (CBM-associated) antigen IL-13 receptor $\alpha 2$ (IL13R $\alpha 2)$. Upon stimulation with IL13R $\alpha 2^{+}$ GBM cells, the CD8+ CAR T cells exhibited robust short-term effector function but became rapidly exhausted. By comparison, the CD4+ CAR T cells persisted after tumor challenge and sustained their effector potency. Mixing with CD4+ CAR T cells failed to ameliorate the effector dysfunction of CD8+ CAR T cells, while surprisingly, CD4+ CAR T cell effector potency was impaired when coapplied with CD8 ${ }^{+}$T cells. In orthotopic GBM models, CD4+ outperformed CD8+ CAR T cells, especially for long-term antitumor response. Further, maintenance of the CD4+ subset was positively correlated with the recursive killing ability of CAR T cell products derived from CBM patients. These findings identify CD4+ CAR T cells as a highly potent and clinically important T cell subset for effective CAR therapy.
\end{abstract}

Authorship note: SJF and CEB are co-senior authors.

Conflict of interest: Patents associated with this work have been licensed by Mustang Bio. Inc., for which SJF and CEB receive royalty payments (patent no. PCT/US2015/051089).

Submitted: December 12, 2017

Accepted: April 12, 2018

Published: May 17, 2018

\section{Reference information:}

JCI Insight. 2018;3(10):e99048. https://doi.org/10.1172/jci. insight. 99048 .

\section{Introduction}

Chimeric antigen receptors (CARs) are synthetic molecules that redirect $\mathrm{T}$ cells to eradicate tumors through specific recognition of surface proteins expressed on tumor cells (1-3). CAR T cell therapy is an approach being explored in the treatment of multiple cancer types, especially exhibiting potent responses in patients with $\mathrm{CD} 19^{+}$hematological malignancies (4-7). The application of CAR T cells to solid tumors, however, has been obstructed by the validation of appropriate tumor-associated antigens and the known immune-suppressive effects of the tumor microenvironment $(1,2,8)$. Our group has focused on advancing the application of CAR $T$ therapy against glioblastoma (GBM), a lethal solid tumor of the CNS for which standard treatments only modestly improve patient outcome (9). IL-13 receptor $\alpha 2$ (IL13R $\alpha 2$ ) is a high-affinity receptor for the cytokine IL-13 and is preferentially expressed in GBM cells as compared with normal brain tissue $(10,11)$. Although further evidence is needed to address the functional significance of IL13R $\alpha 2$ in GBM, its expression is associated with a refractory mesenchymal phenotype and poor prognosis $(12,13)$. Our group has developed CAR T cells targeting IL13R 2 , which specifically recognize and kill GBM, including tumor-initiating cells that are often resistant to standard therapies (14-16). Clinical trials evaluating intracranial administration of IL13R $\alpha 2-C A R$ T cells for the treatment of GBM find that the therapy is well tolerated $(17,18)$, and one case report showed the dramatic response of a patient with recurrent GBM to regionally delivered CAR T cells (18). These preclinical and clinical results illustrate the therapeutic potential of locoregionally administered IL13R $\alpha 2-C A R$ T cells for GBM.

Despite the encouraging evidence that demonstrates the safety and potency of IL13R $\alpha 2-C A R$ T cells, the overall response of GBM patients to CAR $\mathrm{T}$ therapy requires further optimization. We have focused on the characterization and refinement of product composition as an important parameter for improving the potency of CAR T cells (19). Additionally, the treatment of large tumor burdens requires CAR T cells to have the capacity to recursively kill, yet repetitive antigen stimulation often drives $\mathrm{T}$ cells to exhaust 
A

CAR-T

(CD4 Undepleted) CD8+ CAR-T

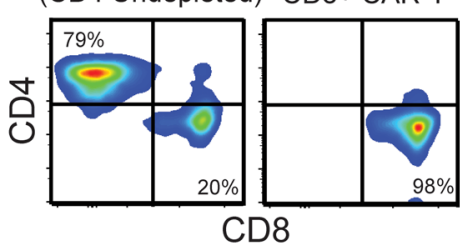

C
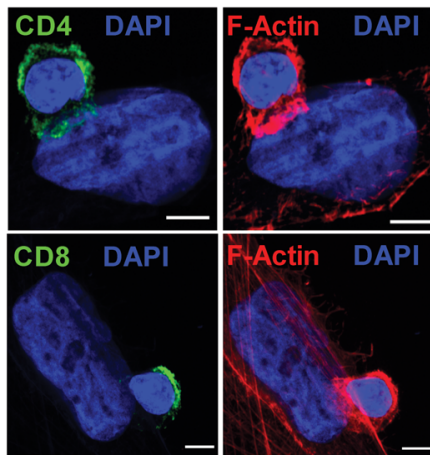

B

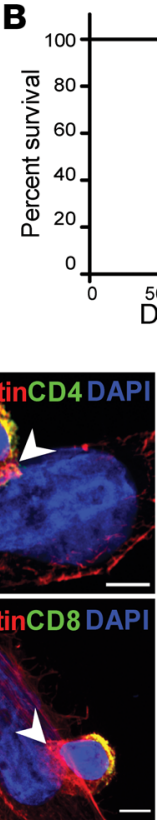

E

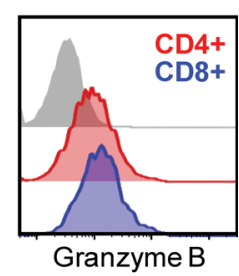
Days post $\mathrm{T}^{150}$ cell injection

D

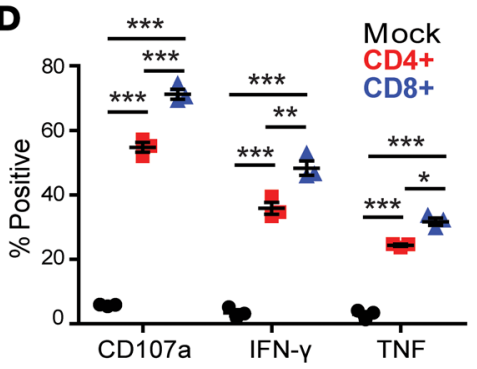

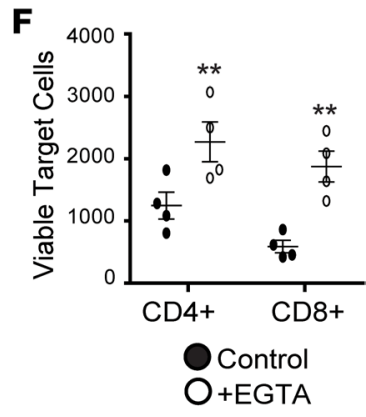

Figure 1. CD4+ CAR T cells are essential for long-term antitumor efficacy and elicit direct cytotoxicity. (A) Flow cytometric analysis of CD4/CD8 composition of IL13R $\alpha 2$-specific CAR T cells with (CD8+ CAR T) or without CD4 depletion. (B) ffLuc ${ }^{+}$PBT030-2 GBM cells (expressing endogenous IL13R $\alpha 2$ ) were stereotactically implanted into the right forebrain of NSC mice $\left(1 \times 10^{5}\right.$ cells/mouse). On day 8 after tumor implantation, mice $(n=6-7$ per group) received either no treatment (Tumor only) or intracranial treatment with $1 \times 10^{6}$ untransduced T cells (Mock), CD4 undepleted CAR T cells, or CD8 ${ }^{+}$CAR T cells. Kaplan Meier survival analysis was shown with the Log-rank (Mantel Cox) test to compare the CD4 $4^{+}$undepleted CAR T cell and CD8 ${ }^{+}$CAR T cell treated groups. (C) Immunofluorescence of CD4/CD8 (green), F-actin (red), and DAPI (blue) of CD4+ or CD8+ CAR T cells following 3-hour coculture with PBT030-2 CBM cells. The polarization of F-actin (arrowhead) indicates immune synapse formation. Scale bar: $5 \mu$ m. (D) CD107a and intracellular cytokine staining of purified CD4+ ${ }^{+}$or CD8 ${ }^{+}$CAR T cells after a 5-hour coculture with PBT030-2 CBM cells $(E: T=1: 1), n=3$ replicates. ${ }^{* * *} P<0.001$ using 1-way ANOVA analysis with Bonferroni's multiple comparison test. (E) Intracellular staining of granzyme B on CD4 ${ }^{+}$and CD8 $8^{+}$CAR T cells after $24-h o u r$ coculture with PBT030-2 GBM cells (E:T = 1:1). (F) PBT030-2 GBM cells were cocultured with CD4+ or CD8 ${ }^{+}$CAR T cells $(E: T=1: 2)$ in the presence/absence of EGTA for 24 hours, and the numbers of viable GBM cells were enumerated, $n=4$ replicates. ${ }^{* *} P<0.01$ using an unpaired Student's $t$ test. All data are representative of 3 different donors; data represents \pm SEM.

and lose antitumor potency $(20,21)$. Thus, a critical goal for advancing CAR T cell therapy is the ability to manufacture CAR T cells that are capable of maintaining a long-term antitumor potential. One of the many approaches for improving the CAR $\mathrm{T}$ cell product focuses on the selection of specific $\mathrm{T}$ cell subsets to optimize antitumor efficacy. Specifically, the memory-associated properties of tumor-targeting $\mathrm{T}$ cells have been proven to correlate with their potency after adoptive transfer (22-24). To exploit T cell memory for CAR T cell therapy, we and others have focused on central memory $\mathrm{T}$ cells $(\mathrm{Tcm})$, a population that mediates long-term engraftment and antitumor immunity after adoptive transfer (22, 25-27). Therefore, we have established a clinical manufacturing platform that genetically engineers enriched Tcm to express an IL13R 2 2-targeted CAR for GBM treatment, which is used in our current clinical study (19) (also see ClinicalTrial.gov NCT02208362)

Another important characteristic of CAR $\mathrm{T}$ cell products is the ratio of $\mathrm{CD}^{+}$and $\mathrm{CD}^{+}$subsets. Although $\mathrm{CD}^{+} \mathrm{T}$ cells have long been considered as the primary cytotoxic population, CD4-mediated antitumor effects have also been observed (28-32). When administered to tumor-bearing mice, $\mathrm{CD}^{+} \mathrm{T}$ cells with tumor-specific TCRs were found to both mediate direct cytotoxicity against tumor cells and to provide helper function to evoke intrinsic antitumor immune responses $(28,31)$. Furthermore, in melanoma patients receiving immunocheckpoint blockade, a neoantigen-specific Th1 population was identified to account for the antitumor effect $(32,33)$. Similarly, $\mathrm{CD} 4^{+} \mathrm{CAR} \mathrm{T}$ cells have also demonstrated their antitumor activity in preclinical models of hematological and solid tumors (34-36). In particular, the presence of a CD4 ${ }^{+}$subset correlated with CAR T persistence in solid tumors (34). Together, these findings suggest an essential role of CD4-mediated immune responses against tumors, which is also highlighted by some ongoing clinical studies where $\mathrm{CD}^{+}$doses are precisely controlled $(37,38)$. However, although $\mathrm{CD} 4^{+} \mathrm{CAR} \mathrm{T}$ cells are able to elicit direct cytotoxic effects against hematological and solid tumors $(34,35,39)$, the relationship between their "helper" and "cytotoxic" activities remains unclear, making it difficult to discern how the CD4 ${ }^{+}$subset 
A CD4+ CD8+
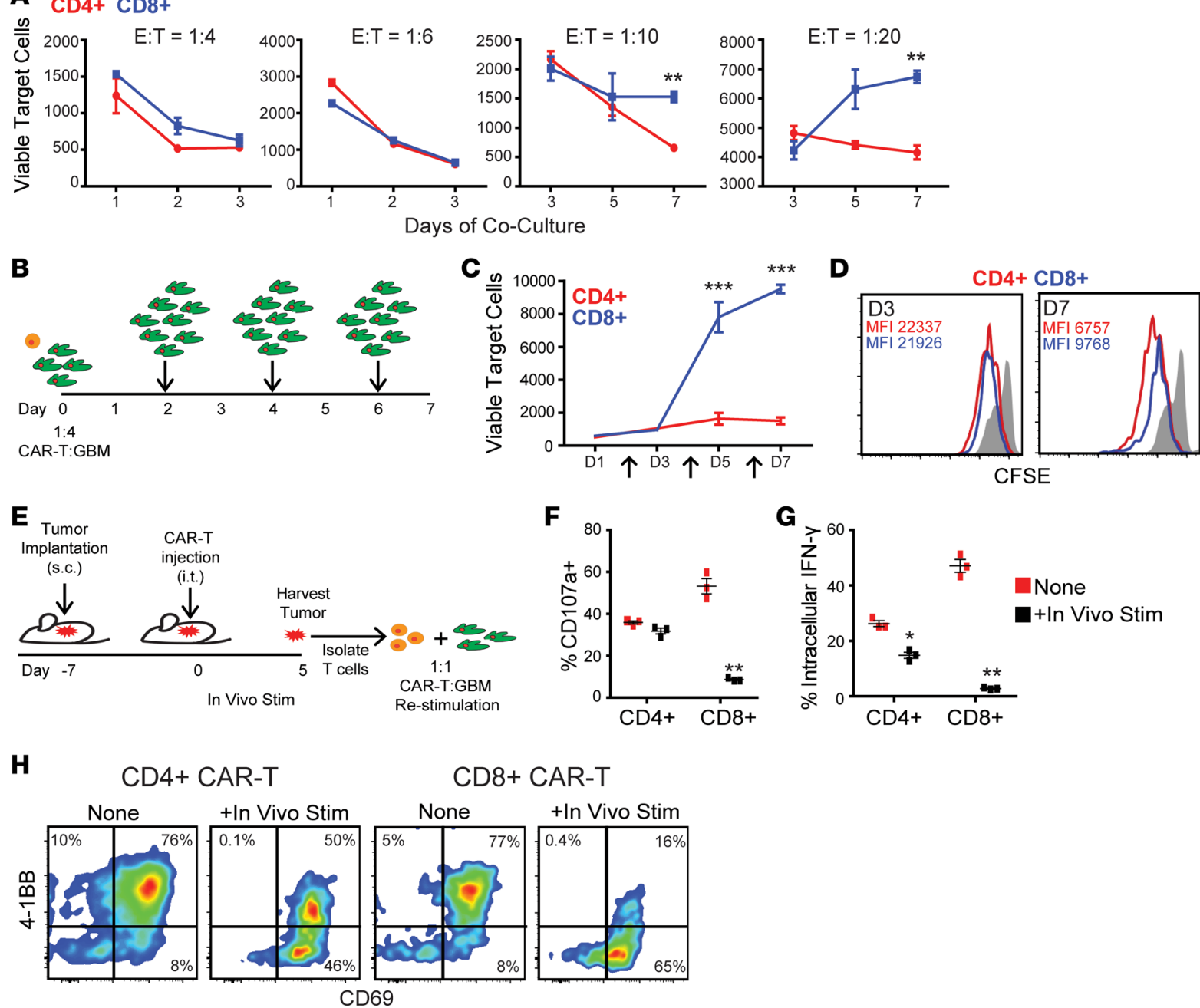

Figure 2. CD4+ CAR T cells retain effector potency after repetitive tumor challenge. (A) PBTO30-2 CBM cells were cocultured with CD4 ${ }^{+}$or CD8 ${ }^{+}$CAR $T$ cells at E:T ratios of 1:4, 1:6, 1:10, and 1:20, and the numbers of viable tumor cells were enumerated at the denoted time points. $n=3$ replicates per time point. ${ }^{*} P<0.01$ using an unpaired Student's $t$ test. (B) Schema of repetitive tumor challenge assay. CAR T cells were cocultured with PBT030-2 CBM cells (4,000 T cells; 16,000 GBM cells; E:T = 1:4) and rechallenged with 32,000 GBM cells every other day. (C) Remaining viable tumor cell numbers were quantified at the indicated time points during the rechallenge assay (arrows indicate tumor rechallenge). $n=3$ replicates per data point. ${ }^{* *} P<0.001$, unpaired Student's $t$ test comparing the CD4 $4^{+}$and $\mathrm{CD} 8^{+}$groups at the indicated time points. (D) CFSE-labeled, repetitively tumor challenged CD4 $4^{+}$and $\mathrm{CD} 8^{+}$CAR T cell were analyzed for CFSE intensity (gated on CD19+ $T$ cells) to determine their proliferation status at D3 and D7. (E-H) Activation potential after in vivo tumor stimulation. (E) Isolated CD4+ or CD8 ${ }^{+}$CAR T cells were administered to tumors via intratumoral injection and harvested after 5 days for in vitro restimulation with PBT030-2 cells (E:T = 1:1, equivalent CAR [CD19+] T cell number across different groups) to evaluate their activation potential. (F-H) In vivo tumor stimulated CD4 ${ }^{+}$and $C D 8^{+}$CAR T cells were evaluated for their activation potential through degranulation (F), intracellular IFN- $\gamma(\mathbf{C})$, and surface expression of activation markers CD69 and 4-1BB $(\mathbf{H})$ following in vitro restimulation. $(\mathbf{F}$ and $\mathbf{G}) n=3$ replicates. ${ }^{*} P<0.05,{ }^{*} P<0.01$ unpaired Student's $t$ test compared with the non-in vivo-stimulated cells (None). All data are representative of 3 different donors; data represents \pm SEM.

contributes to maintaining CAR T cell potency, especially against solid tumors, which requires long-term persistence of CAR activity. Moreover, there has been a lack of comparison between $\mathrm{CD} 4^{+}$and $\mathrm{CD} 8^{+} \mathrm{CAR}$ $\mathrm{T}$ cells regarding their kinetics and mechanisms of cytotoxicity.

In this report, we demonstrate a potent tumor-targeting capability of CD4+ IL13R $\alpha 2$-CAR T cells. $\mathrm{CD}^{+}$CAR T cells mediated CD8-independent GBM eradication and maintained function even after repetitive tumor challenge. In contrast, $\mathrm{T}$ cell exhaustion and subsequent effector dysfunction occurred more rapidly in the $\mathrm{CD} 8^{+}$subset upon encountering tumor cells, which was not reversed by the inclusion of $\mathrm{CD} 4^{+} \mathrm{CAR} \mathrm{T}$ cells, resulting in the loss of $\mathrm{CD} 8^{+} \mathrm{T}$ cell effector activity. Consistently, $\mathrm{CD} 4^{+}$ but not $\mathrm{CD} 8^{+} \mathrm{CAR} T$ cells were found to mediate long-term efficacy against GBM both in vitro and in vivo. Our findings highlight the clinical importance and necessity of the $\mathrm{CD} 4^{+}$subset for effective CAR therapy. 
A
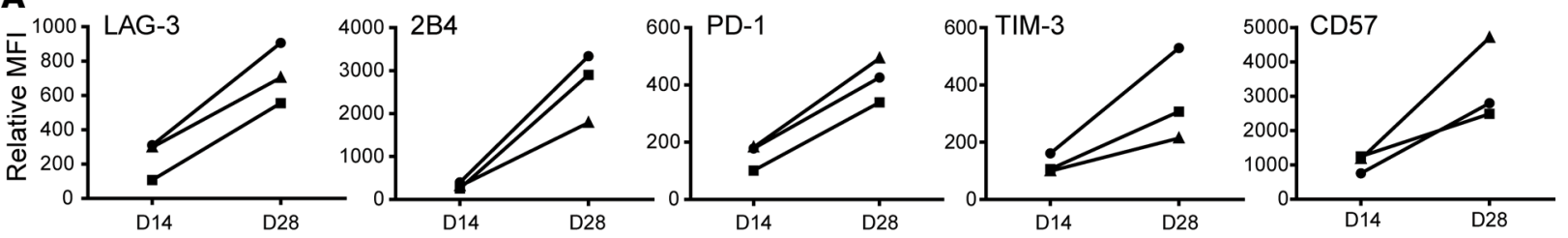

B

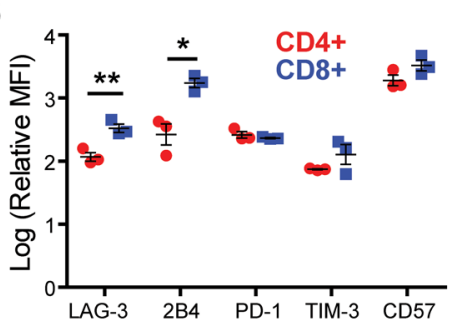

C
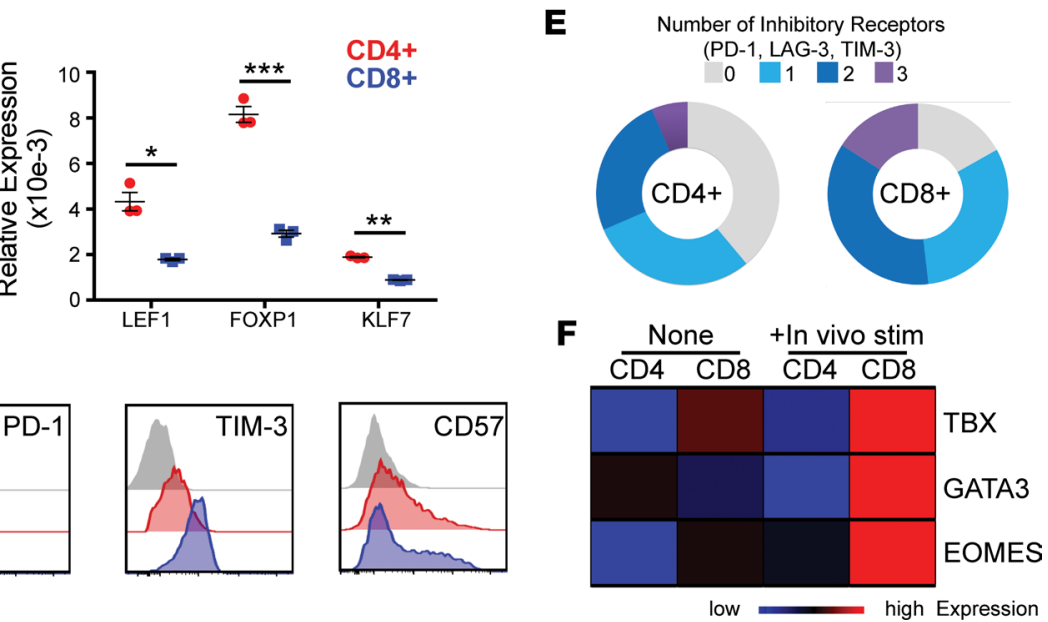

D

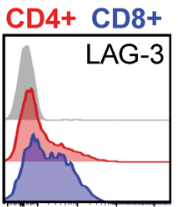

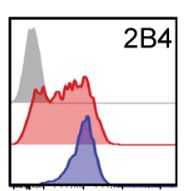

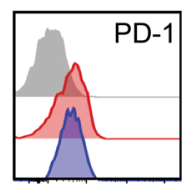

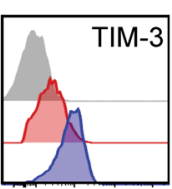

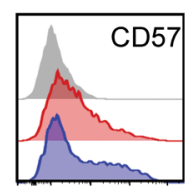

TBX

GATA3

EOMES

low high Expression

Figure 3. Activation-induced exhaustion occurred mainly in CD8 ${ }^{+}$T cells. (A) Expression of inhibitory receptors on CAR T cells (not CD4+ or CD8 ${ }^{+}$enriched) engineered from 3 different donors, which underwent regular 14-day culture (D14) or extended in vitro culture (D28) after CAR transduction. (B) Plot of relative mean fluorescence intensity (MFI, Log scale) of inhibitory receptor staining (with isotype MFI subtracted out) in gated CD4 ${ }^{+}$and CD8 ${ }^{+}$subsets after extended in vitro culture from 3 different donors. (C) mRNA expression of T cell memory-associated transcription factors in isolated CD4 ${ }^{+}$and CD8 ${ }^{+}$ engineered T cells after extended in vitro culture, detected by quantitative PCR (qPCR), $n=3$ replicates. (B and C) ${ }^{*} P<0.05$, ${ }^{* *} P<0.01$, and ${ }^{* * *} P<0.001$ when comparing $\mathrm{CD}^{+}$and $\mathrm{CD} 8^{+}$groups using an unpaired Student's $t$ test; data represents \pm SEM. (D-F) $C D 4^{+}$and CD8 ${ }^{+}$CAR T cells were analyzed after in vivo tumor stimulation. (D) Flow cytometric histograms depicting inhibitory receptor expression (gray peaks represent isotype control). (E) Graphic representation of the coexpression of PD-1, TIM-3, and LAG. (F) Relative mRNA expression of T cell terminal differentiation-associated transcription factors as determined by qPCR. (D-F) Data are representative of 3 different donors.

\section{Results}

The $C D 4^{+}$compartment is required for prolonged antitumor effect and mediates direct cytotoxicity. For anti-GBM therapy, we have previously constructed and characterized a second-generation CAR that specifically targets IL13R $\alpha 2$. The construct harnesses a membrane-bound human IL-13 (E13Y) mutein as the targeting domain, while incorporating a $\mathrm{CD} 3 \zeta \mathrm{T}$ cell activation signal and a 4-1BB (CD137) costimulatory signal (19). The CAR cassette also includes a T2A ribosomal skip sequence followed by a truncated CD19 sequence (CD19t), which acts as a marker for CAR-transduced cells. To be consistent with the clinical manufacturing platform of our CAR T products $(18,25,26)$, enriched Tcm were selected as the starting population for manufacturing IL13R $\alpha 2$-specific CAR $\mathrm{T}$ cells in these studies. Tcm was isolated through depletion of CD14, CD25, CD45RA, and positive selection of CD62L (Supplemental Figure 1A; supplemental material available online with this article; https://doi.org/10.1172/jci.insight.99048DS1). The final CAR T cell product primarily consisted of $\mathrm{Tcm}\left(\mathrm{CD} 62 \mathrm{~L}^{+}, \mathrm{CD} 45 \mathrm{RO}^{+}\right)$with a minor effector memory $\mathrm{T}$ cell (Tem, CD62L- $\mathrm{CD}^{-} 5 \mathrm{RO}^{+}$) population (Supplemental Figure 1B). To investigate the contribution of the $\mathrm{CD}^{+}$subset on the overall antitumor activity, we depleted CD4 ${ }^{+} \mathrm{T}$ cells from the bulk of IL13R $\alpha 2-$ CAR-engineered $\mathrm{T}$ cells through negative selection (Figure 1A and Supplemental Figure 1). The antitumor efficacy of these CD4-depleted $\mathrm{CD}^{+} \mathrm{CAR} T$ cells was evaluated and compared with the CD4-undepleted CAR T cells against orthotopic xenografts of the patient-derived IL13R $\alpha 2^{+}$GBM line PBT030-2 $(12,19)$. Adoptive transfer of CAR T cells into the tumor recapitulates the delivery route of anti-GBM CAR T cells in our clinical studies $(15,17,18)$. In these GBM xenografts, treatment with CD4-undepleted CAR T cells (containing $79 \% \mathrm{CD}^{+}$and $21 \% \mathrm{CD}^{+} \mathrm{T}$ cells) led to long-term survival over 250 days, while CD4-depleted CAR T cells efficiently mediated tumor regression yet was followed by tumor relapse (Figure $1 \mathrm{~B}$ and Supplemental Figure 2). These results strongly suggested that the $\mathrm{CD} 4^{+}$subset is necessary for a potent and prolonged antitumor effect of CAR T cells. 
A
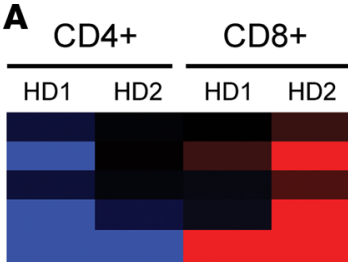

C18orf54

CD86

DIAPH3

DTL

CCNA2

LAG3

MKI67

KIF15

NCAPG

CENPE

PRR11

CCNB2

DEPDC1

TPX2

ENTPD5

IFI16

ARAP2

EOMES

SETBP1

NAP1L3

TMEM2

SNORD35B

SCARNA17

ISG20

IDH2

MLKL

TMEM140

NAB1

PLOD2

HSPA4L

RCBT

PON3

PON3

SATB1
B

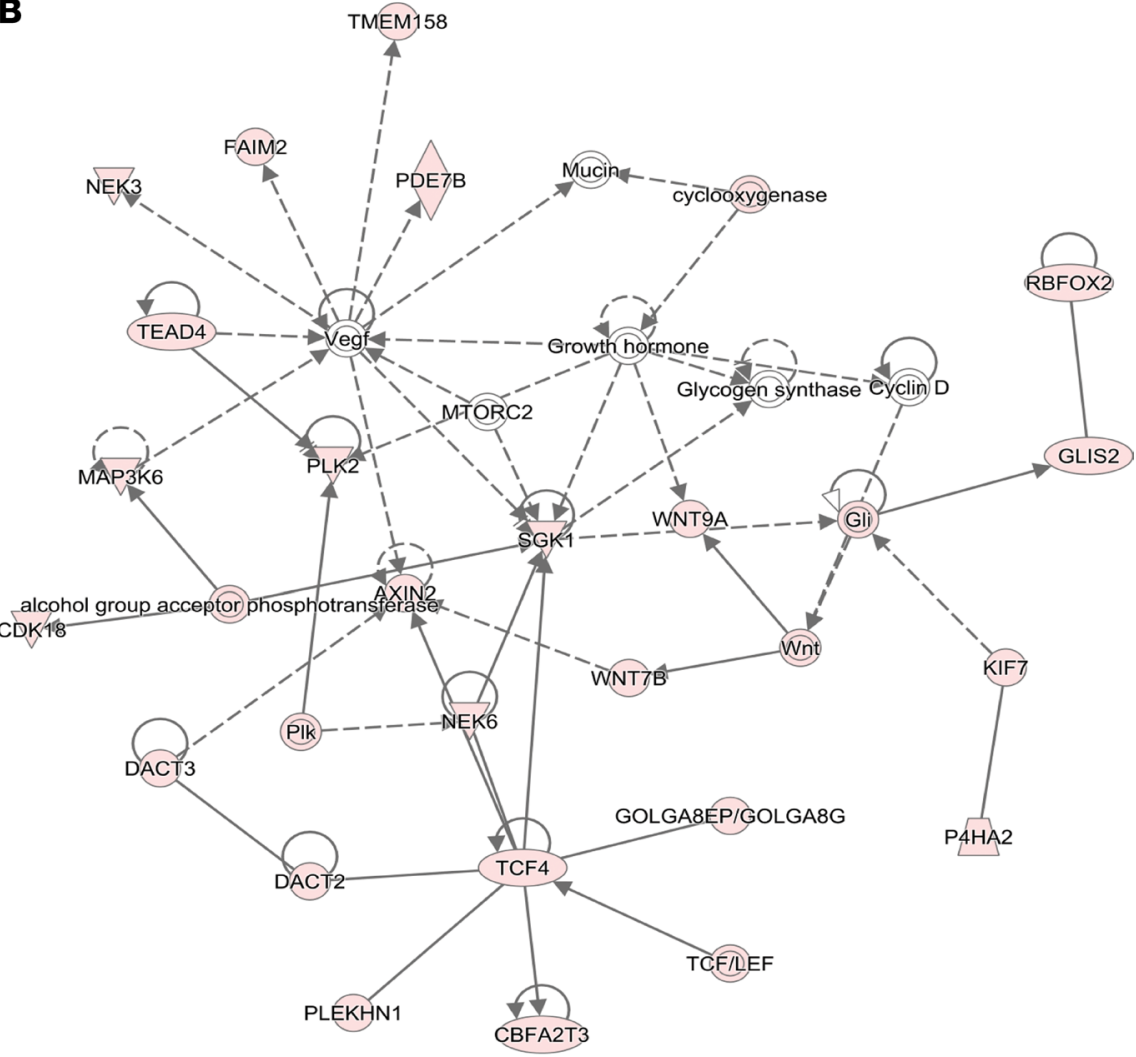

Figure 4. Transcriptional analysis of tumor stimulated CD4 ${ }^{+}$and CD8+ CAR T cells. RNA-seq analysis was performed on isolated CD4+ and CD8 ${ }^{+}$CAR T cell subsets from 2 different donors (HD1 and HD2) after in vivo PBT030-2 tumor stimulation. (A) Heatmap of exhaustion-associated genes that are shared between $\mathrm{CD}^{+}$and $\mathrm{CD} 8^{+} \mathrm{T}$ cells based on a previous study (48). (B) Ingenuity Pathway Analysis of the network with the highest score shown in Table 1.

Since $\mathrm{CD} 4^{+} \mathrm{T}$ cells have been reported to mediate antitumor activity in the absence of the $\mathrm{CD} 8^{+}$subset through either TCR $(21,28,40)$ or CAR $(34,35,38)$ signaling, we directly compared the function of purified $\mathrm{CD} 4^{+}$and $\mathrm{CD} 8^{+}$IL13Ra2-CAR T cells (Supplemental Figure 1) following short-term in vitro stimulation with GBM cells. We first observed that CD4+ IL13R $\alpha 2$-CAR T cells formed structures typical of an immune-synapse at the $\mathrm{T}$ cell-tumor interface, which resembled $\mathrm{CD} 8^{+} \mathrm{CAR} \mathrm{T}$ cells (Figure 1C). The CD4 $4^{+} \mathrm{CAR} \mathrm{T}$ cells were also able to independently degranulate and express IFN- $\gamma$, TNF- $\alpha$, and granzyme B after tumor stimulation (Figure 1, D and E). Notably, consistent with other studies using short-term in vitro cytotoxic assays $(34,35)$, we observed a greater proportion of CD107a- and IFN- $\gamma$-producing $\mathrm{CD} 8^{+}$than $\mathrm{CD} 4^{+} \mathrm{CAR}$ T cells, suggesting a more rapid activation of $\mathrm{CD} 8^{+} \mathrm{T}$ cells upon target stimulation. Further, we blocked granule exocytosis with the calcium chelator EGTA (41), which resulted in a reduced tumor cell killing efficiency in both $\mathrm{CD} 4^{+}$and $\mathrm{CD} 8^{+} \mathrm{CAR} T$ cells (Figure 1F), demonstrating the granzyme B/perforin-dependent cytotoxicity of both subsets. Therefore, both $\mathrm{CD}^{+}$and $\mathrm{CD} 8^{+} \mathrm{CAR} T$ cells appeared to mediate cytotoxic effects against GBM cells via a similar degranulation-mediated mechanism, and we were motivated to further investigate the potential difference(s) in antitumor efficacy between the $2 \mathrm{~T}$ cell subsets.

$C D 4^{+} C A R T$ cells outperform $C D 8^{+} T$ cells in maintaining effector potency. To better distinguish the cytotoxic potential between the 2 subsets, we first performed a cell killing assay in which $\mathrm{CD} 4^{+}$or $\mathrm{CD} 8^{+}$ IL13Ra2-CAR T cells were cocultured with GBM cells at effector/target (E:T) ratios of 1:4 and 1:6. Under such conditions, no difference in cytotoxicity was observed between $\mathrm{CD} 4^{+}$and $\mathrm{CD} 8^{+} \mathrm{CAR} \mathrm{T}$ cells, as both subsets effectively eliminated almost all target cells over a 3-day coculture (Figure 2A left 2 plots and Supplemental Videos 1 and 2). We then increased the potential tumor challenge by reducing the E:T ratios to $1: 10$ and 1:20, and extending the coculture time up to 7 days. Here, under these experimental settings, the $\mathrm{CD} 4^{+} \mathrm{T}$ cells mediated a better control of target cell numbers (Figure $2 \mathrm{~A}$, 


\section{Table 1. Pathways enriched in CD4+ CAR T cells after tumor stimulation}

\begin{tabular}{|c|c|}
\hline Score & Top diseases and functions \\
\hline 39 & Embryonic development, organ development, organismal development \\
\hline 28 & Cell-to-cell signaling and interaction, molecular transport, small molecule biochemistry \\
\hline 28 & Cardiovascular system development and function, organismal development, visual system development and function \\
\hline
\end{tabular}

right 2 panels, and Supplemental Videos 3 and 4). Thus, the cytotoxic activity of $\mathrm{CD}^{+} \mathrm{CAR} \mathrm{T}$ cells, which is CD8 independent, was highly efficient at lower effector abundances.

The differential behaviors between the 2 subsets under lower E:T ratios suggested that the effector function of $\mathrm{CD}^{+} \mathrm{T}$ cells were better maintained after multiple rounds of killing. To further evaluate the recursive killing potential, we set up an in vitro tumor rechallenge assay, in which CAR T cells were challenged every other day with GBM cells (Figure 2B). As depicted in Figure 2C, both CD4 ${ }^{+}$and CD8 ${ }^{+}$CAR T cells mediated effective elimination of GBM cells until day 3 (after a single GBM rechallenge, total E:T = 1:12). However, additional GBM tumor challenges resulted in a decreased CD8 ${ }^{+}$CAR T cell cytotoxicy, shown by the insufficient control of tumor cell number (Figure 2C). By contrast, CD4 ${ }^{+} \mathrm{CAR} T$ cells maintained their effector activity even after repetitive tumor challenge in which these CAR T cells were challenged with a total of 28-fold excess of GBM cells (Figure 2C). The lack of CD8 $8^{+}$CAR T cell efficacy was not due to antigen escape, as the expression of IL13R $\alpha 2$ on viable GBM cells was maintained after coculture with $\mathrm{CD} 8^{+}$CAR T cells (Supplemental Figure $3 \mathrm{~A}$ ). Repetitively stimulated $\mathrm{CD} 4^{+}$and $\mathrm{CD} 8^{+}$subsets also displayed comparable stability of CAR expression (Supplemental Figure 3B). While the proliferation status at day 3 was similar between both subsets, $\mathrm{CD} 4^{+}$but not $\mathrm{CD} 8^{+} \mathrm{CAR}$ T cells continued to proliferate after 3 rounds of GBM cell rechallenge (Figure $2 \mathrm{D}$ ), suggesting that the sustained cytotoxic activity of CD $4^{+} \mathrm{CAR}$ $\mathrm{T}$ cells was associated with better $\mathrm{T}$ cell proliferation. Of note, both $\mathrm{CD} 4^{+}$and $\mathrm{CD} 8^{+} \mathrm{CAR} \mathrm{T}$ cells acquired a Tem phenotype after recursive stimulation (Supplemental Figure $3 \mathrm{C}$ ); however, the CD4 $4^{+} \mathrm{CAR} \mathrm{T}$ cells maintained higher expression levels of memory-associated transcription factors (TFs) than the $\mathrm{CD} 8^{+} \mathrm{T}$ cells (Supplemental Figure 3D), suggesting a better preservation of memory properties. The superior recursive killing potential by $\mathrm{CD} 4^{+} \mathrm{CAR} \mathrm{T}$ cells against repetitive tumor challenge was also observed using U251T, another IL13R $\alpha 2^{+}$GBM cell line (Supplemental Figure 3E).

Given the proliferative capacity of $\mathrm{CD}^{+}$over $\mathrm{CD} 8^{+} \mathrm{CAR} \mathrm{T}$ cells during tumor rechallenge, one possibility we considered was that the superior killing efficacy of $\mathrm{CD} 4^{+} \mathrm{CAR} \mathrm{T}$ cells at high E:T ratios could be a result of their sustained viability and/or proliferation rather than a better maintenance of effector activity. To address this possibility, we compared the antigen-dependent activation potential of $\mathrm{CD}^{+}$and $\mathrm{CD}^{+} \mathrm{T}$ cells prestimulated with tumor. When CAR $\mathrm{T}$ cells were prestimulated in vitro with GBM cells (Supplemental Figure 4A), a 30\% decrease in CD107a degranulation potential for CD8 ${ }^{+}$CAR T cells was observed upon restimulation, whereas no significant decrease in degranulation potential was seen for $\mathrm{CD} 4^{+}$ T cells (Supplemental Figure 4B). Next, $\mathrm{CD}^{+}$or $\mathrm{CD}^{+} \mathrm{CAR} \mathrm{T}$ cells were injected intratumorally into large s.c. GBM tumors to stimulate in vivo, and after 5 days, we harvested tumors, enumerated persisting CAR T cells, and evaluated their capability to activate against tumor restimulation (Figure 2E). Notably, we observed fewer $\mathrm{CD} 8^{+} \mathrm{T}$ cells recovered from the tumors compared with $\mathrm{CD} 4^{+} \mathrm{T}$ cells (Supplemental Figure $4 \mathrm{C}$ ), indicating superior intratumoral $\mathrm{T}$ cell survival of the CD4 ${ }^{+}$subset. Further, in vivo-prestimulated $\mathrm{CD}^{+} \mathrm{T}$ cells almost completely lost their ability for antigen-dependent activation, degranulation, and IFN- $\gamma$ production; in contrast, the activation potential was maintained in the stimulated $\mathrm{CD} 4^{+} \mathrm{T}$ cells (Figure 2, F-H). These results suggest that, in addition to superior proliferation, the tumor-prestimulated $\mathrm{CD}^{+} \mathrm{CAR} \mathrm{T}$ cells also maintained better effector activity per single cell compared with $\mathrm{CD} 8^{+} \mathrm{T}$ cells. Taken together, we demonstrate that both $\mathrm{CD}^{+}$and $\mathrm{CD} 8^{+} \mathrm{CAR} \mathrm{T}$ cells displayed cytotoxic function, while the effector potency of $\mathrm{CD} 4^{+} \mathrm{T}$ cells was better sustained after tumor challenge.

$C D 4^{+} T$ cells are less prone to activation-induced exhaustion and differentiation. Activation-induced $\mathrm{T}$ cell exhaustion has been considered a major mechanism for the lack of persistent function during CAR therapy $(42,43)$. Also, long-term antitumor responses are known to be associated with therapeutic $\mathrm{T}$ cells that exhibit a memory 
A

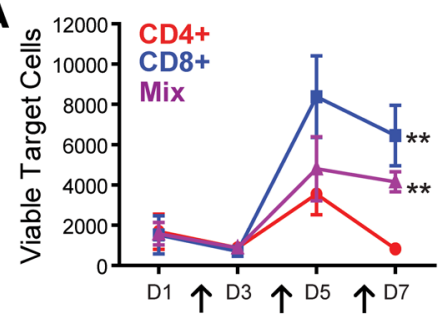

B

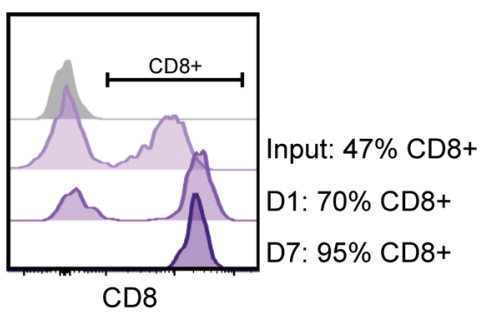

D $\mathrm{CD} 8+\mathrm{CD} 8+$ in mix
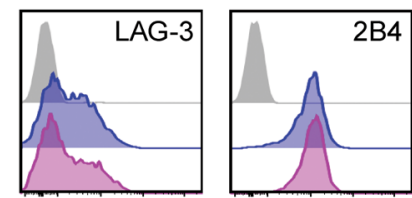

$\mathbf{E}$

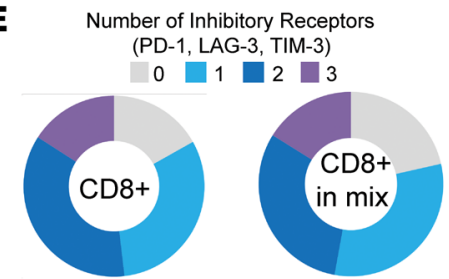

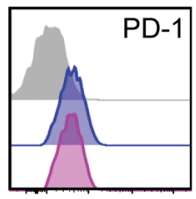

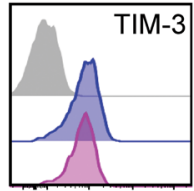

F

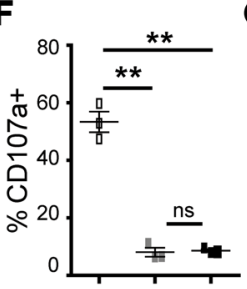

C
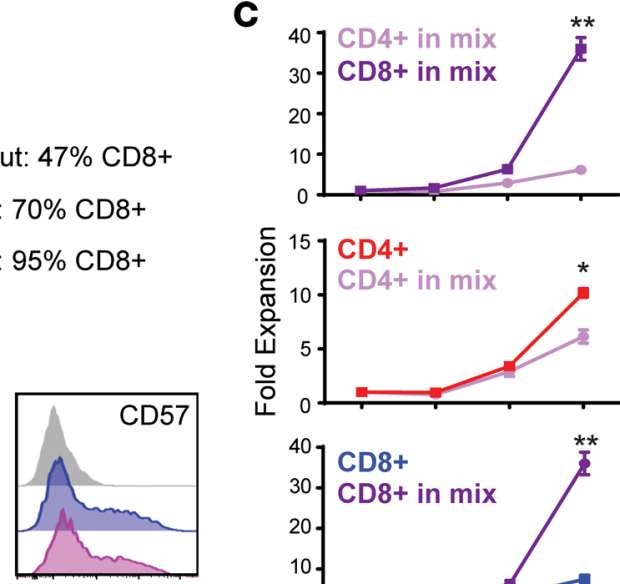

G

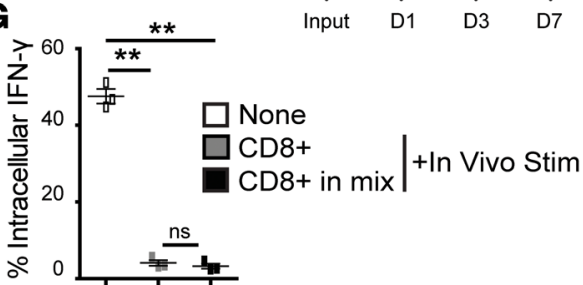

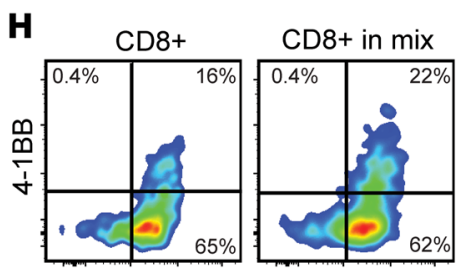

CD69

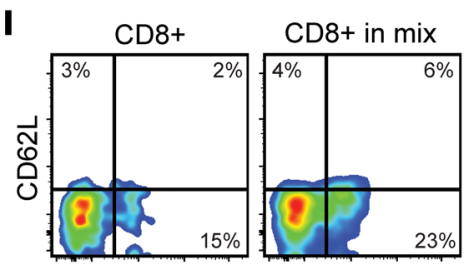

CD45RO

Figure 5. CD4+ CAR T cells do not augment the effector function of CD8+ CAR T cells following tumor stimulation. (A) Viable tumor cell numbers after in vitro repetitive challenge assay as described in Figure $3 \mathrm{~A}$ (arrows represent tumor rechallenge), using CD4+, CD8 ${ }^{+}$, or 1:1 CD4/CD8 mixed CAR T cells (total input $\mathrm{CD}_{19}{ }^{+} \mathrm{T}$ cell number $=4,000$ in each group; $n=3$ replicates per point; ${ }^{* *} P<0.01$, unpaired Student's $t$ test, compared with the CD4 ${ }^{+}$group). (B) $C D 4 / C D 8$ mixed cells were analyzed for $\mathrm{CD} 8^{+} \mathrm{T}$ cell proportions at DO (Input), D1, and D7 during the rechallenge assay. (C) Expansion of CD4+ and CD8 $8^{+}$engineered T cells during rechallenge assay, normalized to the input $\mathrm{CD} 19^{+} \mathrm{T}$ cell number. Comparison of: (top panel) $\mathrm{CD} 4^{+}$vs. CD8 ${ }^{+} \mathrm{T}$ cell expansion within the CD4/CD8 mix; (middle panel) $\mathrm{CD} 4^{+} \mathrm{T}$ cells alone or within the CD4/CD8 mix; and (bottom panel) $\mathrm{CD} 8{ }^{+} T$ cells alone or within the CD4/CD8 mix. $n=3$ replicates per point, ${ }^{*} P<0.05$ and ${ }^{* *} P<0.01$ using an unpaired Student's $t$ test. ( $\mathbf{D}$ and $\mathbf{E}$ ) CD8 ${ }^{+}$or 1:1 CD4/CD8 mixed CAR T cells underwent in vivo stimulation, and the CD8 ${ }^{+}$engineered T cells in both groups were analyzed for inhibitory receptor expression. (F-I) CD8 ${ }^{+}$or 1:1 CD4/CD8 mixed CAR T cells underwent in vivo stimulation, and CD8 ${ }^{+}$engineered T cells were isolated from the tumors and restimulated in vitro. Flow cytometric analysis of degranulation (F), intracellular IFN- $\gamma(\mathbf{C})$, surface expression of activation markers $\mathrm{CD} 69$ and 4-1BB $(\mathbf{H})$, or memory markers (CD62L and CD45RO) (I) was performed and compared between CD8 ${ }^{+}$CAR T cells that were in vivo-stimulated alone $\left(\mathrm{CD}^{+}\right)$or within the $\mathrm{CD} 4 / \mathrm{CD} 8 \mathrm{mix}\left(\mathrm{CD}^{+}\right.$in $\left.\mathrm{mix}\right)$. (F and $\left.\mathbf{G}\right){ }^{*} P<0.01$, using 1-way ANOVA analysis with Bonferroni's multiple comparison test. All data are representative of 3 different donors; data represents \pm SEM.

phenotype $(22,44)$. The difference between $\mathrm{CD} 4^{+}$and $\mathrm{CD} 8^{+} \mathrm{CAR} T$ cells, regarding the capability to maintain effector function, indicated possible differences in exhaustion and memory status between these subsets. To test this hypothesis, we first analyzed the phenotype of $\mathrm{CD}^{+}$and $\mathrm{CD} 8^{+} \mathrm{IL} 13 \mathrm{R} \alpha 2$-CAR $\mathrm{T}$ cells following extended ex vivo culture, a process believed to promote the acquisition of an early-exhaustion phenotype (43). Indeed, a 14-day extended culture upregulated the expression of inhibitory receptors on CAR T cells and also resulted in an increased percentage of $\mathrm{CD} 8^{+} \mathrm{T}$ cells (Figure 3A and Supplemental Figure 5, A and B). Moreover, following extended ex vivo culture, the inhibitory receptors such as LAG-3 and 2B4 exhibited higher expression in the $\mathrm{CD} 8^{+}$subset, while the expression of PD-1, TIM-3, and CD57 did not differ between the subsets (Figure $3 \mathrm{~B}$ and Supplemental Figure 5A). The phenotypic Tcm population $\left(\mathrm{CD}^{2} 2 \mathrm{~L}^{+}, \mathrm{CD} 45 \mathrm{RO}^{+}\right)$was maintained in both subsets after extended culture (Supplemental Figure $5 \mathrm{C}$ ), but the $\mathrm{CD} 4^{+} \mathrm{T}$ cells showed higher expression of memory-associated TFs (Figure 3C). Thus, the $\mathrm{CD} 8^{+} \mathrm{CAR} T$ cells appeared to exhibit a more pronounced early exhaustion and differentiation phenotype than the $\mathrm{CD} 4^{+} \mathrm{T}$ cells during extended culture.

Next, we investigated the exhaustion status of $\mathrm{CD} 4^{+}$and $\mathrm{CD} 8^{+} \mathrm{CAR} \mathrm{T}$ cells after GBM tumor stimulation. Similar to the effects of extended culture, in vivo tumor stimulation resulted in high expression of 

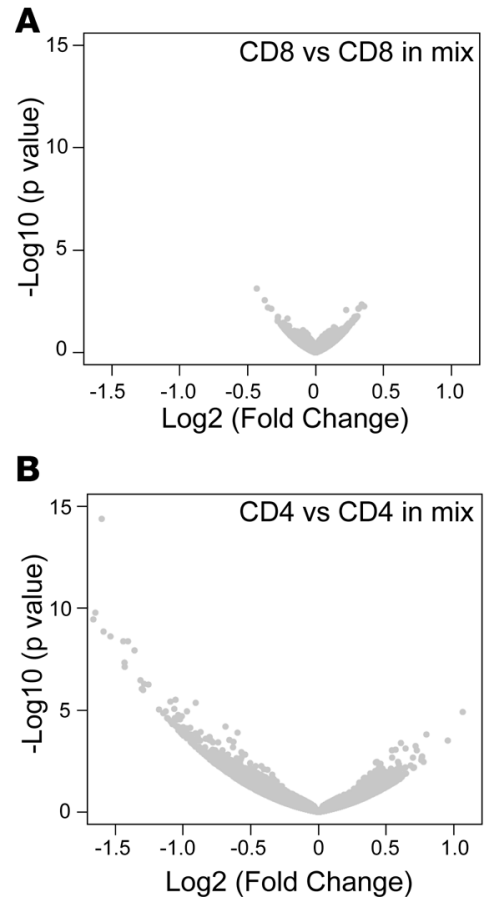
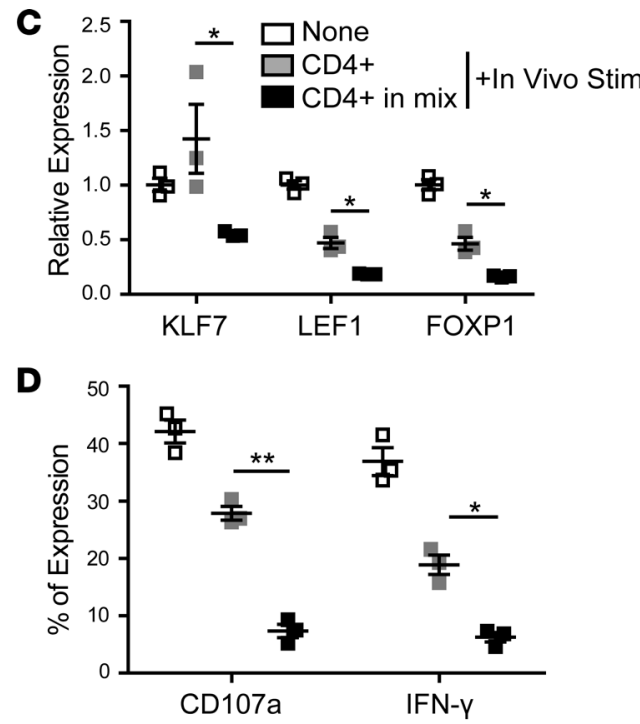

Figure 6. CD4+ CAR T cells fail to maintain effector function if coapplied with $\mathbf{C D 8}^{+} \mathbf{T}$ cells. CD4 ${ }^{+}, \mathrm{CD}^{+}$, or 1:1 CD4/CD8 mixed CAR T cells underwent in vivo stimulation (same total number of $C D 19^{+} T$ cells). (A and $\left.\mathbf{B}\right) \mathrm{CD}^{+}(\mathbf{A})$ and $\mathrm{CD} 4^{+}(\mathbf{B})$ engineered T cells were isolated from tumor and compared for transcriptional profiles when stimulated alone or together with another subset (in mix). The difference between transcriptomes was illustrated by the volcano plot. Fold change and $P$ values were calculated from 2 different donors. (C and $\mathbf{D})$ CD $8^{+}$engineered T cells were isolated from the tumors and were examined for the expression of memory-associated transcription factors, restimulated in vitro, and tested for activation potential by analyzing degranulation (CD107a) and intracellular IFN- $\gamma$. (C and $\mathbf{D}){ }^{*} P<0.05$; ${ }^{* *} P<0.01$, using 1-way ANOVA analysis with Bonferroni's multiple comparison test comparing the "CD4+" and the "CD4+ in mix" groups. Data are representative of 3 different donors.

LAG-3 and 2B4 mainly in CD8 ${ }^{+} \mathrm{T}$ cells (Figure 3D). Moreover, TIM-3, which was only slightly induced in either subset by extended culture (Supplemental Figure 5A), also displayed higher expression on stimulated $\mathrm{CD}^{+}$than $\mathrm{CD}^{+} \mathrm{CAR} \mathrm{T}$ cells (Figure 3D). Importantly, the expression of individual inhibitory receptors may imply a dual-directional effect for $\mathrm{T}$ cell activation, marking both tumor-reactive and exhausted $\mathrm{T}$ cells $(45,46)$. Therefore, we further examined the coexpression of PD-1, LAG-3, and TIM-3, which has been correlated with impaired CAR $\mathrm{T}$ cell effector function (47). The majority of CD4 ${ }^{+} \mathrm{CAR} \mathrm{T}$ cells expressed 0 or 1 , while more than half of the $\mathrm{CD}^{+} \mathrm{CAR} \mathrm{T}$ cells coexpressed 2 or 3 of these inhibitory receptors (Figure 3E). Moreover, stimulated CD8 ${ }^{+} \mathrm{CAR} T$ cells also exhibited higher expression of TFs associated with $\mathrm{T}$ cell terminal differentiation (Figure 3F). Similar results were observed in CAR T cells following in vitro stimulation (Supplemental Figure 5, D-F). These data provided preliminary evidence that $\mathrm{CD} 8^{+} \mathrm{CAR}$ T cells might be more susceptible to activation-induced exhaustion

To better understand the gene expression signatures of stimulated $\mathrm{CD} 4^{+}$and $\mathrm{CD} 8^{+} \mathrm{CAR} \mathrm{T}$ cells, we performed transcriptional profiling on both subsets after in vivo stimulation. Of note, comparison of CD4 ${ }^{+}$ and $\mathrm{CD}^{+} \mathrm{T}$ cell exhaustion is complicated by their lineage-specific molecular profiles. Hence, we specifically focused on the genes that are shared between both exhausted $\mathrm{CD} 4^{+}$and $\mathrm{CD} 8^{+} \mathrm{T}$ cell subsets (48). From this 69-gene list, we further selected a sublist of 35 genes (human orthologs) whose expression was induced in stimulated CAR T cells compared with unstimulated cells (Supplemental Figure 6A). Analysis of these genes revealed an overall higher expression in stimulated CD8 ${ }^{+} \mathrm{CAR} T$ cells than $\mathrm{CD} 4^{+} \mathrm{CAR} \mathrm{T}$ cells (Figure 4A and Supplemental Table 1), suggesting a generally more exhausted status of the CD ${ }^{+}$ CAR T cells after antigen exposure. On the other hand, to understand the mechanism by which CD4+ CAR $\mathrm{T}$ cells sustained better effector activity after tumor stimulation, we performed Ingenuity Pathway Analysis (IPA; https://www.qiagenbioinformatics.com/products/ingenuity-pathway-analysis/) on the genes most enriched in the $\mathrm{CD}^{+} \mathrm{T}$ cells (Supplemental Table 2) and found that the highest-scored network regulates embryonic and organ development (Figure 4B and Table 1). This signaling network, intriguingly, involves 
A

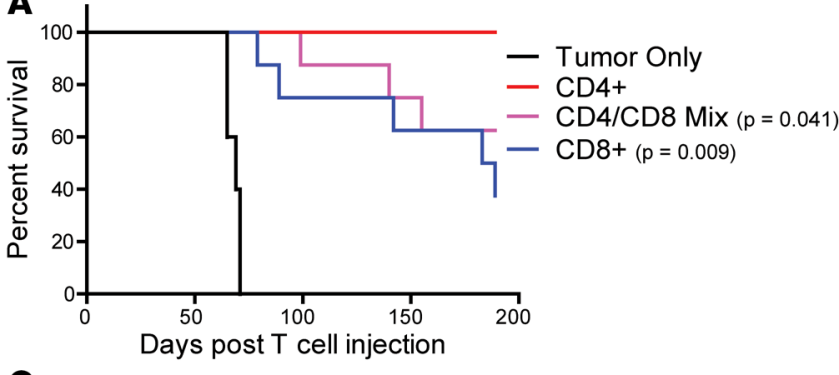

C

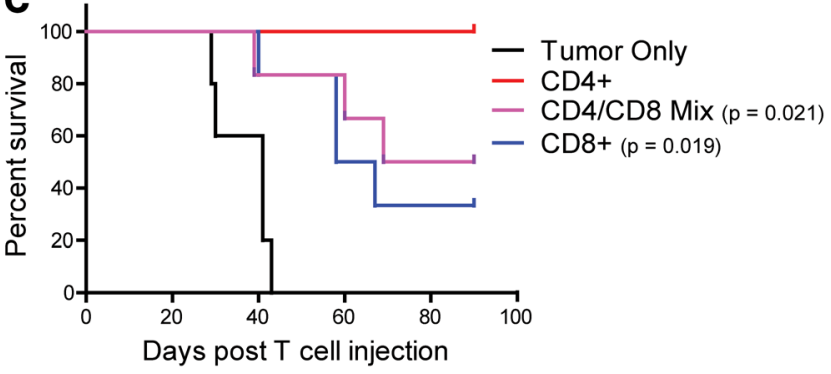

B

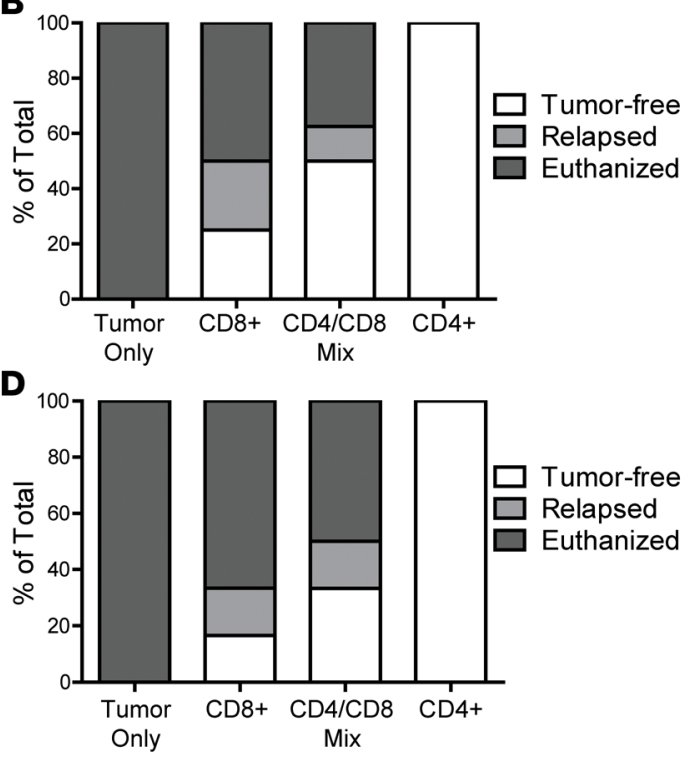

$\mathbf{F}$
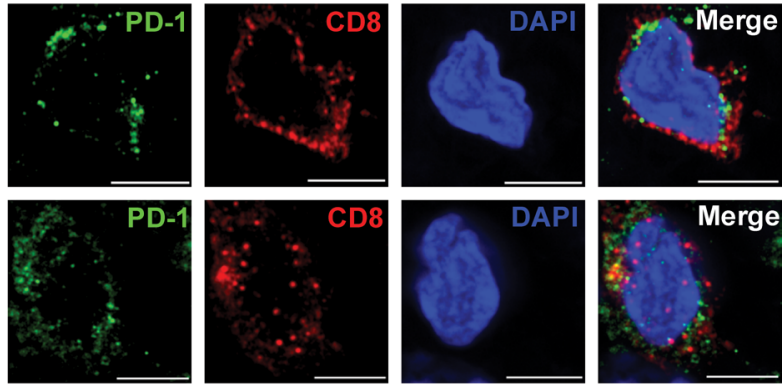

Figure 7. Antitumor activity of CD4 ${ }^{+}$CAR T cells outperform CD8 ${ }^{+}$or CD4 $^{+} /$CD8 $^{+}$CAR T cells in orthotopic GBM xenografts. $f f L u c^{+}$PBTO30-2 (A and B) or PBT103-2 (C and D) GBM cells were stereotactically implanted into the right forebrain of NSG mice $\left(1 \times 10^{5}\right.$ cells/mouse). On day 8 after tumor implantation, mice ( $n=6-7$ per group) received either no treatment (Tumor only); intracranial treatment with $0.5 \times 10^{6} \mathrm{CD}^{+} \mathrm{CAR}^{\mathrm{T}}$ cells or $0.5 \times 10^{6}$ CD8 ${ }^{+}$CAR T cells; or CD4/CD8 mix (a combination of $0.25 \times 10^{6} \mathrm{CD}^{+}$and $0.25 \times 10^{6} \mathrm{CD}^{+}$) CAR T cells. (A and C) Kaplan-Meier survival analysis with $P$ values when compared with the CD4+ CAR T cell group using the Log-rank (Mantel Cox) test. (B and D) At the endpoint of the study (D175 after treatment), mice were categorized by biophotonic imaging as tumor-free, relapsed, or euthanized due to progressive disease. (E) IHC for CD8 (top) and IL13R $\alpha 2$ (bottom) were performed on mouse brain sections with relapsed tumor after treating with CD8 ${ }^{+}$CAR T cells. Red squares indicate the region enlarged in the right. Scale bars: $500 \mu \mathrm{m}$ (left), $25 \mu \mathrm{m}$ (right). (F) Immunofluorescence assay of PD-1 (green) and CD8 (red) were performed on brain sections with relapsed tumor after treating with CD8+ CAR T cells. Scale bars: $5 \mu \mathrm{m}$.

Wnt ligands and the downstream TFs, which are essential in maintaining T cell memory (44) (Figure 4B). Consistently, in vivo-stimulated $\mathrm{CD} 4{ }^{+} \mathrm{CAR} T$ cells also possessed considerable Tcm and Tem proportions, while $\mathrm{CD}^{+} \mathrm{CAR} \mathrm{T}$ cells almost completely lost $\mathrm{CD} 62 \mathrm{~L}$ expression (Supplemental Figure 6B). We thus concluded that, as associated with their superior long-term effector function, CD4 ${ }^{+} \mathrm{CAR} \mathrm{T}$ cells maintained a less-exhausted and potentially more memory-like state than $\mathrm{CD} 8^{+} \mathrm{T}$ cells after tumor stimulation.

To further identify the signaling pathways that distinguish both subsets, we next checked the genes enriched in either $\mathrm{CD} 4^{+}$or $\mathrm{CD} 8^{+} \mathrm{CAR} T$ cells compared with each other, generating another list of genes most differentially expressed in either subsets and analyzed by IPA (Supplemental Table 3). The signaling network with the highest score consisted of genes regulating cell cycle, cellular development, cell death, and cell survival (Supplemental Figure 6, B and C). Importantly, most genes in this network displayed higher expression in $\mathrm{CD}^{+}$, while few were enriched in $\mathrm{CD} 8^{+} \mathrm{T}$ cells (Supplemental Figure $6 \mathrm{D}$ ), suggesting that $\mathrm{CD} 4^{+} \mathrm{CAR} \mathrm{T}$ cells were regulated by prosurvival signaling after stimulation, which might also account for their superior effector function.

Activation-induced $C D 8^{+} C A R$ T cell exhaustion is not ameliorated by $C D 4^{+} T$ cells. $C D 4^{+} \mathrm{T}$ cells have long been identified for their dual functions as helper cells to augment the immune response of $\mathrm{CD} 8^{+} \mathrm{T}$ cells and to directly mediate cytolytic activity (49). Specifically, $\mathrm{CD} 4^{+} \mathrm{T}$ cells are known for the prevention of 

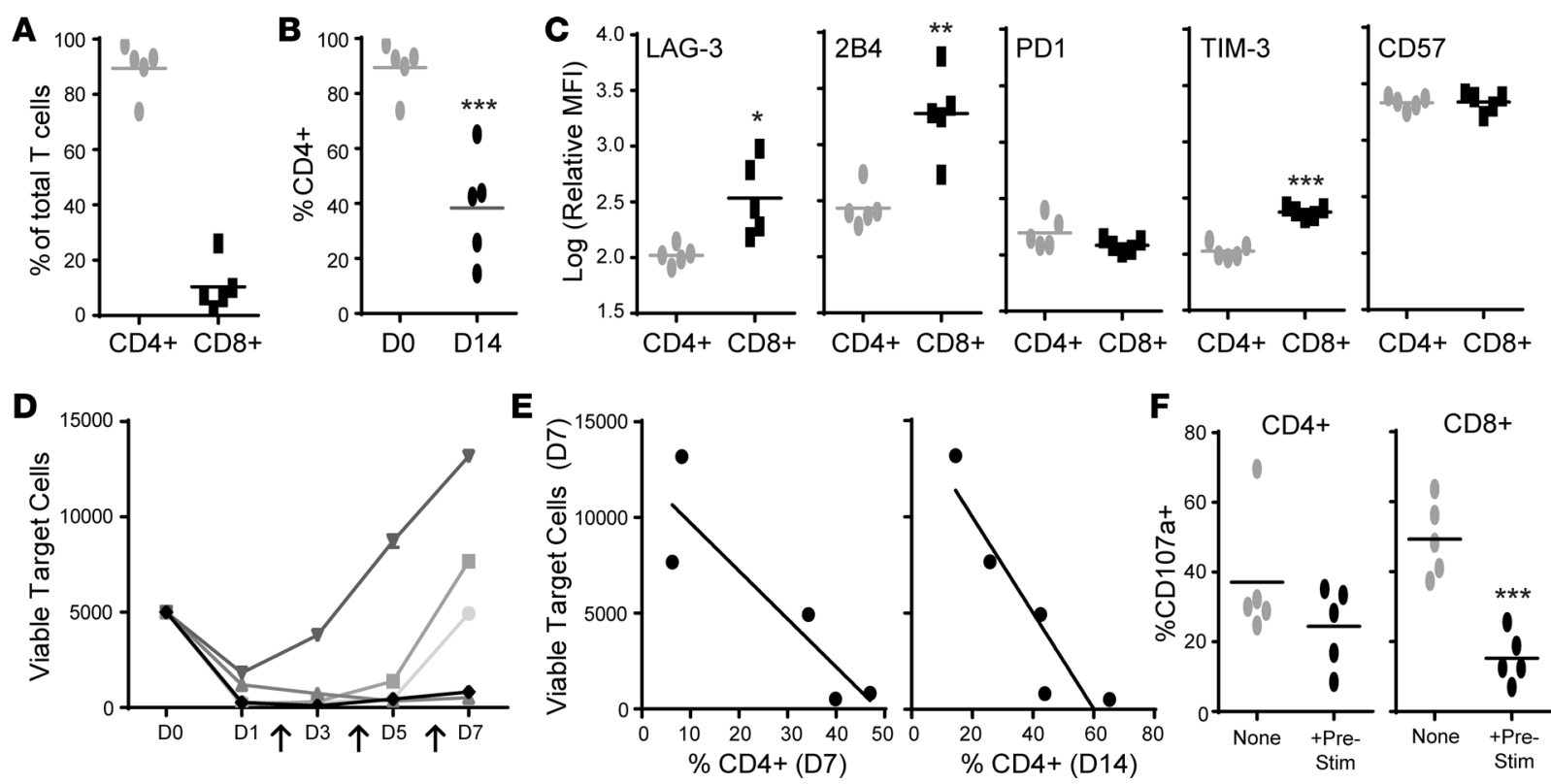

Figure 8. Maintenance of $\mathrm{CD}^{+}$subset predicts effector potency of patient-derived CAR T cells. (A) CD4/CD8 composition CAR T cell therapeutic products engineered from GBM patients $(n=5)$. (B) Percentages of CD4+ T cells in freshly thawed (DO) CAR T cell therapeutic products or after 14 days of extended culture (D14). (C) Expression of inhibitory receptors in CD4+ and CD8 ${ }^{+} T$ cells within the GBM patient CAR T products after extended culture. Horizontal lines indicate mean values; ${ }^{*} P<0.1,{ }^{* *} P<0.01$, and ${ }^{* * *} P<0.001$ when using a paired Student's $t$ test. (D) Each of the 5 GBM patient CAR T cell products were tested for their recursive killing ability (arrows indicate tumor rechallenge). Viable tumor cell numbers were analyzed at denoted time points; $n=3$ replicates per point. (E) The 5 GBM patient products were analyzed for the correlation between CAR T cell killing efficacy (indicated by the remaining viable target cells in D at D7) and the percentage of CD4 $4^{+}$cells at D7 of recursive stimulation (left, $r^{2}=0.7941$ ) or 14 days of extended culture (right, $r^{2}=0.8378$ ). (F) The 5 GBM patient CAR T cell products were prestimulated in vitro and then tested for their activation potential as depicted in Supplemental Figure $3 \mathrm{~A}$; degranulation was analyzed on pregated $C D 4^{+}$or $C D 8^{+}$engineered T cells. Horizontal lines indicate mean values; ${ }^{* *} P<0.001$ when using a paired Student's $t$ test.

$\mathrm{CD}^{+} \mathrm{T}$ cell exhaustion during chronic viral infection (50), providing one mechanism by which $\mathrm{CD}^{+}$ $\mathrm{T}$ cells potentiate immunity through their role as the helpers. Similar observations have also been made with CAR T cells, where mixing $\mathrm{CD} 4^{+}$with $\mathrm{CD} 8^{+} \mathrm{T}$ cells led to improved antitumor efficiency $(35,37$, 38). Our results show that activated CD $4^{+}$CAR T cells secreted more IFN- $\gamma$ and IL- 2 than the CD $8^{+}$ $\mathrm{T}$ cells (Supplemental Figure 7A), consistent with the observations from CAR $\mathrm{T}$ cells targeting other tumor antigens $(35,36,42)$ and suggesting that $\mathrm{CD} 4^{+} \mathrm{CAR} T$ cells might, thus, be able to augment the effector potency of $\mathrm{CD} 8^{+} \mathrm{CAR} T$ cells and that a mixture of both populations would maximize CAR efficacy. To test this hypothesis, we compared a 1:1 ratio of CD4/CD8 CAR T cells to single CD4 ${ }^{+}$or $\mathrm{CD} 8^{+}$subsets using the in vitro repetitive GBM challenge assay (as depicted in Figure 2B). Unexpectedly, while CD4/CD8 mixed CAR T cells did show enhanced cytotoxic activity as compared with CD8 ${ }^{+}$ CAR T cells, they were less effective in tumor cell elimination than CD4+ CAR T cells (Figure 5A). To explain the lack of synergistic effect when mixing $\mathrm{CD} 4^{+}$and $\mathrm{CD} 8^{+} \mathrm{CAR} T$ cells, we speculated that the $\mathrm{CD} 4 / \mathrm{CD} 8$ composition of the mixed $\mathrm{T}$ cells might have changed during the recursive stimulation. Indeed, as shown in Figure 5B, the percentage of $\mathrm{CD} 8^{+} \mathrm{T}$ cells increased during the assay. Particularly, at day 7 after the mixed $\mathrm{T}$ cells had undergone 4 rounds of stimulation, the $\mathrm{CD} 8^{+} \mathrm{T}$ cells comprised over $90 \%$ of the entire $\mathrm{T}$ cell population (Figure $5 \mathrm{~B}$ ). The change of $\mathrm{CD} 4 / \mathrm{CD} 8$ composition was mainly a result of $\mathrm{CD}^{+} \mathrm{CAR} T$ cell proliferation (Figure $5 \mathrm{C}$ ). Specifically, compared with the single subsets, augmented proliferation of $\mathrm{CD} 8^{+} \mathrm{CAR} \mathrm{T}$ cells occurred in the presence of $\mathrm{CD} 4^{+} \mathrm{T}$ cells, while $\mathrm{CD} 4^{+} \mathrm{CAR}$ $\mathrm{T}$ cell expansion was slightly reduced when coapplied with $\mathrm{CD} 8^{+} \mathrm{T}$ cells (Figure $5 \mathrm{C}$ ). Similar results were observed when examining the recovery of in vivo-stimulated CAR T cells (Supplemental Figure $4 \mathrm{C}$ ). The improved $\mathrm{CD} 8^{+} \mathrm{T}$ cell proliferation possibly explained the advantageous effect of mixed CAR $\mathrm{T}$ cells compared with a single $\mathrm{CD} 8^{+} \mathrm{CAR} T$ cell subset. However, when examining the exhaustion phenotype of those $\mathrm{CD} 8^{+} \mathrm{CAR} T$ cells following in vivo or in vitro stimulation, the expression of inhibitory receptors was not affected by the presence of $\mathrm{CD} 4^{+} \mathrm{T}$ cells (Figure 5, D and E, and Supplemental Figure 7, B and C). Furthermore, the presence of $\mathrm{CD} 4^{+} \mathrm{CAR} T$ cells also did not augment the potential of the in vivo-stimulated $\mathrm{CD} 88^{+} \mathrm{CAR} T$ cells to degranulate and produce cytokine (Figure 5, F-H) or protect 
the stimulated CD8 ${ }^{+}$CAR T cells from differentiation (Figure 5I and Supplemental Figure 7, D and E). Therefore, the loss of effector function in $\mathrm{CD} 8^{+} \mathrm{CAR} \mathrm{T}$ cells following tumor challenge was not rescued by $\mathrm{CD} 4^{+} \mathrm{CAR} \mathrm{T}$ cells.

The apparent inhibition of $\mathrm{CD} 4^{+} \mathrm{CAR} \mathrm{T}$ cell expansion when mixing with $\mathrm{CD}^{+} \mathrm{T}$ cells (Figure $5 \mathrm{C}$ ) led to the investigation of whether their effector function was also altered under the mixed condition. Therefore, we performed transcriptional analysis of $\mathrm{CD}^{+}$and $\mathrm{CD} 8^{+} \mathrm{CAR} \mathrm{T}$ cells following in vivo stimulation as a single subset or at a 1:1 mixture. We first noticed that the presence of coapplied $\mathrm{CD} 4^{+} \mathrm{T}$ cells did not cause a significant change in the transcriptional signature of $\mathrm{CD} 8^{+} \mathrm{T}$ cells (Figure 6A), aligned with the lack of amelioration for the acquired exhaustion and loss of memory as depicted above. In contrast, the transcriptional profile of $\mathrm{CD} 4^{+} \mathrm{T}$ cells was dramatically altered in the presence of $\mathrm{CD} 8^{+} \mathrm{T}$ cells (Figure $6 \mathrm{~B}$ ). We further observed that, when coapplied with $\mathrm{CD} 8^{+} \mathrm{T}$ cells, the in vivo-stimulated $\mathrm{CD} 4^{+} \mathrm{T}$ cells expressed less memory-associated TFs and lost the ability to maintain effector activity (Figure 6, C and D). Taken together, these observations indicated that, although $\mathrm{CD} 4^{+} \mathrm{CAR} \mathrm{T}$ cells facilitated $\mathrm{CD} 8^{+} \mathrm{CAR} \mathrm{T}$ cell proliferation, they elicited little protection of the $\mathrm{CD} 8^{+} \mathrm{CAR} \mathrm{T}$ cells from exhaustion and also failed to maintain their own effector function, thus resulting in the lack of synergistic effector activity between these 2 subsets.

Enhanced anti-GBM responses by $C D 4^{+} C A R$ T cells in orthotopic tumor model. The differential capability of $\mathrm{CD}^{+}$and $\mathrm{CD}^{+} \mathrm{T}$ cells in maintaining cytotoxic effects upon tumor challenge led us to investigate whether $\mathrm{CD}^{+} \mathrm{CAR} \mathrm{T}$ cells are superior at eradicating GBM tumors as a single subset. Therefore, we treated orthotopic GBM xenografts with CAR T cells composed of either $100 \% \mathrm{CD} 4^{+}, 100 \% \mathrm{CD} 8^{+}$, or a $50 \%-50 \%$ mixture of both subsets. We also sought to distinguish the efficacy of CAR $\mathrm{T}$ cells with different CD4/CD8 compositions at a reduced effector cell dose of $0.5 \times 10^{6}$ CAR T cells/mouse. Similar with previous results (Figure 1B), complete short-term remission was observed in every treatment group, with a few exceptions observed only in those mice treated with $100 \%$ CD $8+$ CAR T cells (Figure 7A and Supplemental Figure 8A). Long-term antitumor response was then monitored in these animals for over 6 months. Tumor relapse and subsequent mortality was seen in the groups treated with CAR T cells that contained $100 \%$ and $50 \% \mathrm{CD} 8^{+} \mathrm{T}$ cells, while the groups treated with $100 \% \mathrm{CD} 4^{+} \mathrm{CAR} \mathrm{T}$ cells remained tumor free for more than 6 months (Figure 7B and Supplemental Figure 8A). We also evaluated a more aggressive orthotopic GBM model (Figure 7C), and similar outcomes were observed, showing that only the treatment with $\mathrm{CD} 4{ }^{+} \mathrm{CAR} \mathrm{T}$ cells resulted in complete long-term tumor eradication (Figure 7, C and D, and Supplemental Figure 8A). Both GBM cell lines had little expression of HLADR (Supplemental Figure 8C), an MHC-II molecule important for CD4+ TCR recognition (51-53), suggesting that the superior CD4-mediated antitumor effect was not a result of an allogeneic response.

Staining of recurrent tumors showed the expression of IL13R $\alpha 2$ (Figure 7E), suggesting that antigen loss was also not responsible for the lack of long-term $\mathrm{T}$ cell antitumor efficacy. Intriguingly, although adoptively transferred $\mathrm{CD} 8^{+} \mathrm{T}$ cell dysfunction has been shown to be associated with the rapid depletion of the injected cells (54), we did detect $\mathrm{CD} 8^{+} \mathrm{T}$ cells in the relapsed tumors 6 months after injection with CD4/CD8 mixed or CD8+-only CAR T cells (Figure 7E and Supplemental Figure 8B). The PD-1 expression on these cells (Figure $7 \mathrm{~F}$ ) suggests that, rather than being eliminated, intratumoral $\mathrm{CD}^{+} \mathrm{T}$ cells can persist in an exhausted state without antitumor potential, even within the immunocompromised context of our mouse model. Together, these data suggested that $\mathrm{CD} 4^{+} \mathrm{CAR} \mathrm{T}$ cells alone are sufficient in mediating efficacious and long-lasting tumor eradication.

Retention of the $\mathrm{CD}^{+}$subset is correlated with improved killing potency for GBM patient-derived CAR T cell products. Having demonstrated the advantageous antitumor activity mediated by $\mathrm{CD} 4^{+} \mathrm{CAR} \mathrm{T}$ cells, we next analyzed the CD4/CD8 composition and cytotoxicity of 5 CAR T cell products from GBM patients produced in accordance with our clinical manufacturing platform (NCT02208362). Although our previous studies focused on the superior persistence of $\mathrm{CD} 8^{+} \mathrm{T}$ cell products derived from enriched Tcm cells over Tem (26), one of the most notable features of Tcm-derived CAR T cell products is the high percentage of the $\mathrm{CD}^{+}$subset (average $85 \% \pm 9 \%$, Figure $8 \mathrm{~A}$ ). After extended ex vivo culture, similar to the CAR T cells engineered from healthy donors described above, GBM patient-derived CAR T cells also displayed a decrease of the $\mathrm{CD}^{+}$percentage and early exhaustion phenotype (Figure $8 \mathrm{~B}$ and Supplemental Figure 9A), with more inhibitory receptors expressed in the $\mathrm{CD}^{+}$subset (Figure $8 \mathrm{C}$ ). Tcm phenotype was not significantly affected by extended culture (Supplemental Figure 9B). Employing the recursive in vitro tumor challenge assay (as depicted in Figure 2B), differential killing potential was observed between these patient CAR T cell products (Figure 8D). While recursive tumor cell stimulation resulted in a decrease in CD4 ${ }^{+}$ 
percentage within all CAR T cells, the extent of CD4 reduction differed between patient products (Supplemental Figure 9C). Importantly, our analysis revealed a positive correlation between recursive killing potency and maintenance of $\mathrm{CD}^{+} \mathrm{CAR} \mathrm{T}$ cells following tumor stimulation (Figure $8 \mathrm{E}$, left), while no correlation was found when looking at the $\mathrm{CD}^{+}$subset (data not shown). Similar correlation was observed when comparing cytotoxic potency with the maintenance of the $\mathrm{CD} 4^{+}$subset after extended culture (Figure $8 \mathrm{E}$, right). Moreover, stimulation of patient-derived cell products with tumor cells resulted in a greater loss of CAR activation potential, as assessed by decreased antigen-dependent CD107a degranulation upon secondary tumor challenge, in $\mathrm{CD} 8^{+} \mathrm{CAR} \mathrm{T}$ cells as compared with $\mathrm{CD} 4^{+} \mathrm{T}$ cells (Figure $8 \mathrm{~F}$ ). Together, our data demonstrate that patient-derived CAR $\mathrm{T}$ cell products can differ in their ability to retain the CD4 ${ }^{+}$ subset following tumor challenge, which is correlated with their cytotoxic activity.

\section{Discussion}

In this study, we provide mechanistic insights into the unexpected superior antitumor potency of $\mathrm{CD}^{+}$ CAR T cells over the $\mathrm{CD}^{+}$subset. More specifically, we demonstrate that $\mathrm{CD} 4^{+} \mathrm{CAR} \mathrm{T}$ cells maintained better effector function against tumor challenge, while $\mathrm{CD} 8^{+} \mathrm{CAR} T$ cells more readily acquired an exhausted phenotype and displayed a greater loss of effector potency. The cytotoxicity of $\mathrm{CD}^{+} \mathrm{CAR} \mathrm{T}$ cells is mediated through the granzyme B/perforin pathway in a CD8-independent manner, and the production of IFN- $\gamma$ and IL- 2 suggests a Th1 differentiation, which is one of the key features of cytotoxic CD4 ${ }^{+} \mathrm{T}$ cells $(28,33)$. Our results have suggested that $\mathrm{CD} 4^{+} \mathrm{CAR} \mathrm{T}$ cells are a clinically important subset mediating long-term antitumor responses for CAR therapy. Indeed, by analyzing CAR T cells derived from GBM patients, we showed a correlation between the capability to maintain the CD4 ${ }^{+} \mathrm{CAR} T$ cell subset and the sustainability of cytotoxic activity (Figure 8).

One of the challenges to efficiently evaluate the functionality of engineered $\mathrm{T}$ cells has been the lack of in vitro functional assays that are reflective of in vivo antitumor potency. Activity assessed by in vitro short-term cytolytic assays (e.g., chromium release assays) are oftentimes inversely correlated with their in vivo antitumor function $(42,43,55)$, which is likely attributed to the high $\mathrm{E}$ :T ratio that renders the outcome of these assays less sensitive to $\mathrm{T}$ cell exhaustion (21). Indeed, $\mathrm{CD} 8^{+} \mathrm{CAR}$ effector function appeared to be greater than or comparable with $\mathrm{CD}^{+} \mathrm{T}$ cells during our short-term cytotoxicity assays. Here, we established the in vitro recursive tumor killing assay (Figure $2 \mathrm{~B}$ ) to distinguish the antitumor response between $\mathrm{CD}^{+}$and $\mathrm{CD}^{+} \mathrm{CAR} \mathrm{T}$ cells, the results of which were highly predictive to the long-term antitumor function against orthotopic GBMs. In vitro assays like this one, with more rigorous tumor challenges, could be a more effective approach for assessing the potency of CAR T cell products.

The superior CD4-mediated antitumor immunity against GBM is consistent with a previous report evaluating $\mathrm{CD}^{+}$mesothelin-specific CAR T cells (34). Similarly, that study also used regional administration of second-generation CAR $\mathrm{T}$ cells to target solid tumors. The mesothelin-CAR $\mathrm{T}$ cells were generated from peripheral blood mononuclear cells (PBMCs) without Tcm enrichment, and we also observed similar results for the superior recursive killing potential of $\mathrm{CD}^{+} \mathrm{CAR} \mathrm{T}$ cells generated from unselected $\mathrm{T}$ cells (Supplemental Figure 10), demonstrating the consistency across different manufacturing platforms. However, conflicting results have been observed using CAR $\mathrm{T}$ cells targeting CD19+ hematological tumors, in which a larger number of $\mathrm{CD}^{+} \mathrm{T}$ cells was required to get equivalent antitumor effects, as compared with $\mathrm{CD} 8^{+}$ $\mathrm{T}$ cells (35). Such a discrepancy might be due to the differences in tumor models (such as the expression of costimlatory molecules) and/or differences in delivery routes of CAR T cells, since regional delivery results in CAR T cells encountering a high density of tumor antigen shortly after administration, where CD8 ${ }^{+} \mathrm{T}$ cells would be expected to lose function more rapidly. On the other hand, consistent across all these studies was the CD8-independent cytotoxicity of $\mathrm{CD}^{+} \mathrm{CAR} \mathrm{T}$ cells. Effective $\mathrm{CD} 4^{+} \mathrm{T}$ cell cytotoxicity has been shown to require high-affinity interaction between the receptor and tumor antigens (56). Similarly, in comparison with $\mathrm{T}$ cells engineered with first-generation CAR constructs, those harboring second-generation CARs exhibited strengthened CD4-mediated antitumor efficacy (34). High-affinity binding was also verified between the IL-13 and IL13R $22(57,58)$, which was the structural basis of the CAR used in this study. Given the fact that CAR design usually involves high-affinity interaction with the targeted antigen (2), we would suggest that the cytotoxicity of $\mathrm{CD}^{+} \mathrm{T}$ cells are critical for CAR $\mathrm{T}$ cell efficacy across different platforms.

$\mathrm{T}$ cell exhaustion has long been considered as one of the major hurdles against effective antitumor responses, and it has been rigorously investigated in both $\mathrm{CD}^{+}$and $\mathrm{CD} 8^{+}$subsets $(21,42,43,59)$. The comparison of exhaustion status between these 2 subsets, however, remains complicated, as the majority 
of exhaustion-associated genes are identified as present in one subset but not the other (48). Here, we used a combination of functional evaluations, transcriptional signatures, and phenotypic analysis to comprehensively compare the exhaustion status of $\mathrm{CD}^{+}$and $\mathrm{CD} 8^{+} \mathrm{CAR} \mathrm{T}$ cells. All these approaches consistently revealed that the $\mathrm{CD}^{+} \mathrm{T}$ cells were more prone to exhaustion after tumor challenge. Intriguingly, one recent study revealed that TCR engagement led to distinct CAR activity between $\mathrm{CD} 4^{+}$and CD8 ${ }^{+}$ CD19-CAR T cells (36). Here, the use of naive-depleted T cells (CD45RA depletion, Supplemental Figure 1A) - which have been shown to reduce alloreactivity $(60,61)$ - and the lack of HLA-DR expression on tumor cells, a MHC II molecule critical for $\mathrm{CD}^{+}$TCR recoginition (51-53), together suggested that allogeneic responses did not account for the superior $\mathrm{CD} 4^{+} \mathrm{CAR}$-mediated antitumor response observed in this study. Therefore, the differential effector activities between $\mathrm{CD} 4^{+}$and $\mathrm{CD} 8^{+} \mathrm{CAR} \mathrm{T}$ cells might be both TCR dependent and independent. Importantly, both studies revealed that intrinsic differences between the $\mathrm{CD}^{+}$and $\mathrm{CD} 8^{+} \mathrm{T}$ cells account for their behaviors after $\mathrm{CAR}$ activation, which might be conserved across different CAR designs.

Further, IPA allowed for an unbiased approach to compare $\mathrm{CD} 4^{+}$and $\mathrm{CD} 8^{+} \mathrm{CAR} \mathrm{T}$ cells. In the $\mathrm{CD}^{+}$subset, several $\mathrm{T}$ cell memory-associated genes stood out over the $\mathrm{CD} 8^{+} \mathrm{T}$ cells, supporting the notion that inhibiting $\mathrm{T}$ cell effector differentiation would support a less exhausted status and promote long-term efficacy $(62,63)$. Notably, the differential memory status between the 2 subsets occurred even before antigen engagement during extended culture and was further magnified after tumor stimulation (Figure 3C and Supplemental Figure 3D). These results also suggested that $\mathrm{T}$ cell differentiation may have taken place before any observable changes in surface markers (comparing Figure 3C with Supplemental Figure 3D). Intriguingly, the CD4 subset-associated/enriched genes also include multiple factors within the Wnt signaling pathway, such as AXIN2, LEF, and Wnt ligands. Wnt signaling plays an essential role in facilitating stem cell self-renewal, as well as promoting memory $\mathrm{T}$ cell generation $(23,64,65)$. These data imply that the more activated Wnt signaling in $\mathrm{CD}^{+}$, as compared with $\mathrm{CD} 8^{+}$, CAR $\mathrm{T}$ cells may maintain the $\mathrm{T}$ cells at a proliferative and yet less-differentiated state upon stimulation. Therefore, the transcriptional analysis here revealed the possible mechanism by which $\mathrm{CD}^{+}$ CAR T cells maintained activity after stimulation, while also providing insights about the potential for exploiting Wnt activators to enhance T cell potency (66).

It is widely accepted that $\mathrm{CD} 4^{+} \mathrm{T}$ cell activity helps $\mathrm{CD} 8^{+} \mathrm{T}$ cell effector function, leading to effective immune responses (67). However, less is understood about distinguishing the helper function of CAR-engineered $\mathrm{CD} 4^{+} \mathrm{T}$ cells from their direct role in tumor killing. In this study, we show that CD4 ${ }^{+} \mathrm{CAR} \mathrm{T}$ cells did augment the proliferation of $\mathrm{CD}^{+} \mathrm{T}$ cells but, unexpectedly, did not ameliorate $\mathrm{CD} 8^{+} \mathrm{CAR} \mathrm{T}$ cell effector potency. $\mathrm{CD} 8^{+} \mathrm{CAR} \mathrm{T}$ cells displayed a similar propensity to rapidly acquire an exhaustion phenotype after tumor challenge, with or without the inclusion of $\mathrm{CD}^{+} \mathrm{T}$ cells. Moreover, the effector function, including the proliferative and cytotoxic potential, of $\mathrm{CD} 4^{+} \mathrm{CAR} \mathrm{T}$ cells appeared to be inhibited by the coapplied $\mathrm{CD}^{+} \mathrm{T}$ cells. One explanation for this effect is the rapid activation and subsequent nutrient/ cytokine consumption by $\mathrm{CD} 8^{+} \mathrm{T}$ cells. As a result, after repetitive tumor challenge, the mixed CAR $\mathrm{T}$ cells were predominantly $\mathrm{CD} 8^{+} \mathrm{T}$ cells (Figure $5 \mathrm{~B}$ ) and were less efficient for tumor elimination than the $\mathrm{CD} 4^{+}$ CAR $\mathrm{T}$ cells alone. Indeed, it has been controversial whether mixing $\mathrm{CD} 4^{+}$with $\mathrm{CD} 8^{+} \mathrm{CAR} \mathrm{T}$ cells has a synergistic antitumor effect across different preclinical studies of CAR T cells treating hematological and solid tumors (34-36), suggesting that the optimal ratio could be influenced by platform-specific differences in CAR designs and/or tumor models. However, our study and others have consistently highlighted the importance for maintaining a CD4+ CAR T cell compartment for effective antitumor activity $(34,36)$.

Optimizing the $\mathrm{T}$ cell product potency is one of the many approaches being explored to potentiate CAR therapy, especially against solid tumors. IL $13 R \alpha 2$ is an attractive tumor target, given its preferential expression on GBM cells in comparison with other neural tissues. Moreover, intracranial infusion of IL13R $\alpha 2-C A R$ T cells have also been well tolerated in GBM patients $(17,18)$. Hence, efforts to improve the potency of the CAR product and to augment the therapy is well warranted. Our current clinical platform, utilizing enriched $\mathrm{Tcm}$ consisting of both $\mathrm{CD}^{+}$and $\mathrm{CD} 8^{+}$subsets to replace the previous $\mathrm{CD} 8^{+}$-only product, illustrates some of our progresses toward CAR refinement (19). Here, the superior antitumor effect of $\mathrm{CD}^{+} \mathrm{CAR} \mathrm{T}$ cells over $\mathrm{CD} 8^{+} \mathrm{T}$ cells provides further advancement for optimizing $\mathrm{T}$ cell production. We also noticed that the percentage of $\mathrm{CD}^{+} \mathrm{CAR} \mathrm{T}$ cells increased after extended ex vivo expansion (Supplemental Figure 8B), unveiling the necessity to limit the culture time when manufacturing CAR T cells. Furthermore, we observed from our clinical results that infused CAR T cells potentially evoked an intrinsic 
antitumor immune response (18). $\mathrm{CD}^{+} \mathrm{T}$ cells have been shown to mediate systemic immunity, which is essential for long-term tumor eradication $(68,69)$. Therefore, it is important to recognize that the CD4 CAR T cells may also have indirect antitumor effects in patients. Therefore, overall, these findings lead us to propose that, when evaluating clinical responses following CAR therapy, the frequency and quality of the $\mathrm{CD}^{+} \mathrm{CAR} \mathrm{T}$ cells within the product and/or persisting in tumor microenvironment following adoptive transfer might be exploited to reflect or predict effective therapy.

\section{Methods}

Supplemental Methods are available online with this article.

DNA constructs. The IL13R $\alpha 2$-targeted CAR construct used throughout the study is the same as currently used in our clinical study of patients with recurrent/refractory GBM (available on ClinicalTrials.gov, NCT02208362) $(18,19)$. The construct is composed of a human GM-CSF receptor $\alpha$ chain leader peptide, a human IL-13 with an E13Y mutation, an IgG4 spacer with 2 point mutations (L235E and N297Q) (70), a CD4 transmembrane domain, a human 4-1BB costimulatory domain, and the cytoplasmic domain of human $\mathrm{CD} 3 \zeta$. A truncated CD19 was also introduced in the construct to allow for potential enrichment and tracking of transduced cells. The firefly luciferase-GFP (ffLuc-GFP) construct for tumor biophotonic imaging was generated as described previously (14).

Tcm isolation, CAR transduction, and CD4/CD8 enrichment. Blood products were obtained from healthy donors under protocols approved by the $\mathrm{COH}$ IRB, and Tcm isolation followed the procedures described in previous studies $(19,25)$. In brief, PBMCs were isolated by density gradient centrifugation over FicollPaque (GE Healthcare) and then underwent sequential rounds of CliniMACS/AutoMACS (Miltenyi Biotec) depletion to remove CD14-, CD25-, and CD45RA-expressing cells, followed by a CD62L-positive selection for Tcm. Tcm were stimulated with Dynabeads Human T expander CD3/CD28 (Invitrogen) at a 1:3 ratio ( $\mathrm{T}$ cell/bead) and transduced with lentivirus to express CAR (multiplicity of infection $[\mathrm{MOI}]=0.5$ ) in X-VIVO 15 (Lonza) containing 10\% FCS with $5 \mu \mathrm{g} / \mathrm{ml}$ protamine sulfate (APP Pharmaceuticals), $50 \mathrm{U} /$ $\mathrm{ml}$ recombinant human IL-2 (rhIL-2), and $0.5 \mathrm{ng} / \mathrm{ml} \mathrm{rhIL}-15$. Cultures were then maintained at $37^{\circ} \mathrm{C}, 5 \%$ $\mathrm{CO}_{2}$ under the same condition of media and cytokines; cytokines were supplied every other day. On day 7 after transduction, the CD3/CD28 Dynabeads were removed from cultures using the DynaMag-50 magnet (Invitrogen). Cultures were propagated for 14 or 28 days as indicated in figure legends (Figure 3, A-C, and Supplemental Figure 5, 28-day expansion; all remaining figures, 14-day expansion). To separate the CD4 ${ }^{+}$ or $\mathrm{CD}^{+}$subsets, CAR T cells at day 14 after transduction underwent a magnetic selection processes using the EasySep Human $\mathrm{CD}^{+}$or $\mathrm{CD}^{+} \mathrm{T}$ cell isolation kits (Stemcell Technologies), respectively, and the negative fraction was collected. All procedures are depicted in Supplemental Figure 1A. All experiments were repeated using CAR T cells from 3 independent donors unless specifically mentioned in figure legends.

GBM cell culture. Primary brain tumor (PBT) cells (PBT030-2 and PBT103-2) were obtained from GBM patient resections at $\mathrm{COH}$ under protocols approved by the $\mathrm{COH}$ IRB and maintained as described previously $(14,15)$. To generate cells for in vivo biophotonic imaging, these cells were engineered to express the ffLuc reporter gene as previously described (14).

Flow cytometry. Cells were harvested and stained as described previously (70). T cell phenotype was detected using fluorochrome-conjugated antibodies against CD3, CD4, CD8, and CD45 (BD Biosciences) (Supplemental Table 5). Transgene expression was determined by staining for the truncated CD19 (BD Biosciences), and all engineered $\mathrm{T}$ cells were gated as the $\mathrm{CD}^{+}, \mathrm{CD} 45^{+}$, and $\mathrm{CD} 19^{+}$population unless specifically mentioned in figure legends. Memory-associated phenotypes were analyzed with fluorochrome-conjugated antibodies against CD45RO, CD62L, CD27, and CD28 (BD Biosciences). Expression of coinhibitory receptors was detected via the following fluorochrome-conjugated antibodies: PD-1, 2B4 (BioLegend); Lag-3, Tim-3 (eBiosciences), and CD57 (BD Biosciences). T cell function was determined using fluorochrome-conjugated antibodies against CD107a, granzyme B, IFN- $\gamma$ (all BD Biosciences), and TNF- $\alpha$ (Miltenyi Biotec). All samples were analyzed via a Macsquant Analyzer (Miltenyi Biotec) and processed via FlowJo v10. To isolate CAR T cells following in vitro or in vivo stimulation, harvested cells were labeled with fluorochrome-conjugated anti-CD4, -CD8, -CD19, and -CD45 antibodies; $\mathrm{CD}^{+}\left(\mathrm{CD} 4^{+}, \mathrm{CD}^{-}, \mathrm{CD} 19^{+}, \mathrm{CD} 45^{+}\right)$or $\mathrm{CD}^{+}\left(\mathrm{CD} 4^{-}, \mathrm{CD}^{+}, \mathrm{CD} 19^{+}, \mathrm{CD} 45^{+}\right) \mathrm{CAR} \mathrm{T}$ cells were sorted via an Aria SORP cell sorter (BD Biosciences).

In vitro $T$ cell assays. To test for cytotoxicity and activity, PBTs were dissociated with cold accutase (Innovative Cell Technologies) and resuspended in DMEM: F12 (Irvine Scientific) media supplied with 10\% FCS. 
T cells were then washed and resuspended in the same media and added to the PBT cells. To test for degranulation, CAR T cells were incubated with PBT cells for 5 hours in the presence of CD107a antibody and Golgistop protein transport inhibitor (BD Biosciences). After the coculture, cells were harvested, fixed, permeabilized, and stained for intracellular cytokines. Degranulation (CD107a staining) and intracellular cytokine staining were examined by flow cytometry. For cytotoxicity tests, coculture would last for 1-7 days as indicated. After coculture, all cells were harvested and stained with antibodies against CD4, CD8, CD19, and CD45. Remaining tumor cells (CD45 $)$ and CAR T cells $\left(\mathrm{CD} 45^{+} \mathrm{CD} 19^{+} \mathrm{CD} 4^{+}\right.$orCD $\left.45^{+} \mathrm{CD} 19^{+} \mathrm{CD} 8^{+}\right)$was quantified by flow cytometry.

Quantitative PCR. Total mRNA from cultured or sorted T cells was isolated by RNeasy Mini Kit (Qiagen Inc.). cDNA was then synthesized via an Omniscript RT Kit (Qiagen Inc.). Quantitative PCR was performed using SYBR Green PCR Master mix (Applied Biosystems) in a ViiA-7 reverse transcription PCR (RT-PCR) system (Thermo Fisher Scientific). Primers are available in Supplemental Table 4. The comparative $\mathrm{Ct}$ values of genes of interest were normalized to the $\mathrm{Ct}$ value of $\beta$-actin. Then, the $2^{-\Delta c t}$ method was used to determine the relative expression of the genes, while the $2^{-\Delta \Delta c t}$ method was used to calculate the fold changes of gene expression over control.

RNA-seq and gene expression analysis. RNA was isolated as described above and sequenced with Illumina protocols on a HiSeq 2500 to generate 50-bp reads. Sequenced reads were aligned to the human hg38 reference genome with TopHat2 (71). Transcript expression level was quantified by HTSeq (72), and DESeq2 was utilized to identify differentially expressed genes (73). Transcript abundance was quantified as reads per kilobase of transcript per million fragments mapped (RPKM).

GBM xenograft studies. All mouse experiments were approved by the COH IACUC. Orthotopic GBM models were generated using 6- to 8 week-old NOD/SCID/IL2R $\mathrm{R}^{-/}$(NSG) mice as previously described (The Jackson Laboratory) (16). Briefly, on day 0 , ffLuc ${ }^{+}$PBT103-2 cells $\left(1 \times 10^{5}\right)$ were stereotactically implanted into the right forebrain of NSG mice. After 8 days, mice were then treated intracranially with $0.5-1.0 \times 10^{6} \mathrm{CAR} \mathrm{T}$ cells as indicated for each experiment. Tumor volumes were determined by in vivo noninvasive optical biophotonic imaging using a Xenogen IVIS 100 as previously described (14). Mice were also monitored for survival, with euthanasia applied according to the American Veterinary Medical Association Guidelines.

For in vivo CAR T cell stimulation, PBT030-2 cells $\left(5 \times 10^{6}\right)$ were injected s.c. into the left flank of NSG mice. Eight days after tumor implantation, CAR T cells $\left(2 \times 10^{6}\right)$ were injected intratumorally. Tumors were harvested and dissociated 5 days after $\mathrm{T}$ cell injection and processed for CAR T cell sorting.

Immunofluorescence and IHC. PBT cells were dissociated as described above and plated for 12 hours to adhere. T cells were then added to PBT cells and incubated for 3 hours before fixation with $4 \%$ paraformaldehyde (Boston BioProducts Inc.). Fixed cells were incubated with primary and secondary antibodies (Supplemental Table 5). Permeabilization and cytoskeleton staining was performed by an F-actin Visualization Biochem Kit (Cytoskeleton Inc.). Mouse brain harvesting, sectioning, and IHC assays were performed as described previously (14). Immunofluorescence (IF) staining on paraffin-embedded sections followed the procedures of a previous study (64) with minor modifications.

Antibodies used in IF and IHC assays included anti-CD8 (mouse, Dako), anti-IL13R $\alpha 2$ (goat, R\&D Systems), anti-PD1 (rabbit, Abcam), and donkey anti-mouse Alexa 647, donkey anti-goat Alexa 555, and donkey anti-rabbit Alexa 488 (all Invitrogen; Supplemental Table 5).

All slides for IF assays were observed with an LSM Airyscan 880 (Zeiss), and images were processed with Amira (FEI software). The slides for IHC assays were scanned via a NanoZoomer 2.0-HT Digital slide scanner (Hamamatsu) and processed with NDP.view2 (Hamamatsu).

Statistics. Data analysis was performed using Prism v6.0 (GraphPad Software) and presented as stated in individual figure legends. Comparisons were determined using 2-tailed Student's $t$ test (2 groups) or 1-way ANOVA ( 3 or more groups). For the comparison between 3 or more groups, Bonferroni's multiple comparison tests were used to compare all or selected pairs of data $(95 \% \mathrm{CI})$. Comparison of Kaplan-Meier survival data was performed using Log-rank (Mantel-Cox) test. Detailed comparisons in each experiment are described in figure legends.

Study approval. All mouse experiments were approved by the COH IACUC. Mice were also monitored for survival, with euthanasia applied according to the American Veterinary Medical Association Guidelines. Use of all human subjects materials (human CAR T cell production and patient-derived GBM spheres) was approved by the COH IRB. 


\section{Author contributions}

DW, SJF, and CEB designed research studies; DW, BA, RS, AB, and AS conducted experiments; DW, BA, and RS acquired data; DW, DA, and CEB analyzed data; CEB and SJF contributed as resources; DW, DA, JRO, and CEB wrote manuscript; SJF and CEB contributed supervision and funding acquisition.

\section{Acknowledgments}

We thank the Department of Comparative Medicine and the cores of Small Animal Imaging, Analytical Cytometry, Integrative Genomics, and Solid Tumor Pathology, as well as Brenda Chang, Juan Ruiz-Delgado, Xin Yang, and Jared Pollard for their technical assistance. We thank Behnam Badie, Suzette Blanchard, and Michael Barish for their intellectual feedback on this work. This work was supported by the California Institute for Regenerative Medicine (CIRM) grant TR3-05641, NIH grant P30 CA33572 (cores), and research support from Mustang Bio.

Address correspondence to: Christine E. Brown, 1500 East Duarte Road, Duarte, California 91010, USA. Phone: 626.256.4673; Email: cbrown@coh.org.

1. Priceman SJ, Forman SJ, Brown CE. Smart CARs engineered for cancer immunotherapy. Curr Opin Oncol. 2015;27(6):466-474.

2. Sadelain M, Brentjens R, Rivière I. The basic principles of chimeric antigen receptor design. Cancer Discov. 2013;3(4):388-398.

3. Fesnak AD, June CH, Levine BL. Engineered T cells: the promise and challenges of cancer immunotherapy. Nat Rev Cancer. 2016;16(9):566-581

4. Porter DL, Levine BL, Kalos M, Bagg A, June CH. Chimeric antigen receptor-modified T cells in chronic lymphoid leukemia. N Engl J Med. 2011;365(8):725-733.

5. Grupp SA, et al. Chimeric antigen receptor-modified T cells for acute lymphoid leukemia. N Engl J Med. 2013;368(16):1509-1518.

6. Brentjens RJ, et al. CD19-targeted T cells rapidly induce molecular remissions in adults with chemotherapy-refractory acute lymphoblastic leukemia. Sci Transl Med. 2013;5(177):177ra38.

7. Brentjens RJ, et al. Safety and persistence of adoptively transferred autologous CD19-targeted T cells in patients with relapsed or chemotherapy refractory B-cell leukemias. Blood. 2011;118(18):4817-4828.

8. Scarfò I, Maus MV. Current approaches to increase CAR T cell potency in solid tumors: targeting the tumor microenvironment. J Immunother Cancer. 2017;5:28.

9. Van Meir EG, Hadjipanayis CG, Norden AD, Shu HK, Wen PY, Olson JJ. Exciting new advances in neuro-oncology: the avenue to a cure for malignant glioma. CA Cancer J Clin. 2010;60(3):166-193.

10. Debinski W, Gibo DM, Hulet SW, Connor JR, Gillespie GY. Receptor for interleukin 13 is a marker and therapeutic target for human high-grade gliomas. Clin Cancer Res. 1999;5(5):985-990.

11. Almeida LG, et al. CTdatabase: a knowledge-base of high-throughput and curated data on cancer-testis antigens. Nucleic Acids Res. 2009;37(Database issue):D816-D819.

12. Brown CE, et al. Glioma IL13R $\alpha 2$ is associated with mesenchymal signature gene expression and poor patient prognosis. PLoS ONE. 2013;8(10):e77769.

13. Thaci B, Brown CE, Binello E, Werbaneth K, Sampath P, Sengupta S. Significance of interleukin-13 receptor alpha 2-targeted glioblastoma therapy. Neuro-oncology. 2014;16(10):1304-1312.

14. Brown CE, et al. Stem-like tumor-initiating cells isolated from IL13R 22 expressing gliomas are targeted and killed by IL13-zetakine-redirected T Cells. Clin Cancer Res. 2012;18(8):2199-2209.

15. Brown CE, et al. Recognition and killing of brain tumor stem-like initiating cells by CD8+ cytolytic T cells. Cancer Res. 2009;69(23):8886-8893.

16. Kahlon KS, Brown C, Cooper LJ, Raubitschek A, Forman SJ, Jensen MC. Specific recognition and killing of glioblastoma multiforme by interleukin 13-zetakine redirected cytolytic T cells. Cancer Res. 2004;64(24):9160-9166.

17. Brown CE, et al. Bioactivity and Safety of IL13Ra2-Redirected Chimeric Antigen Receptor CD8+ T Cells in Patients with Recurrent Glioblastoma. Clin Cancer Res. 2015;21(18):4062-4072.

18. Brown CE, et al. Regression of Glioblastoma after Chimeric Antigen Receptor T-Cell Therapy. N Engl J Med. 2016;375(26):2561-2569.

19. Brown CE, et al. Optimization of IL13R $\alpha 2$-Targeted Chimeric Antigen Receptor T Cells for Improved Anti-tumor Efficacy against Glioblastoma. Mol Ther. 2018;26(1):31-44.

20. Wherry EJ, Kurachi M. Molecular and cellular insights into T cell exhaustion. Nat Rev Immunol. 2015;15(8):486-499.

21. Malandro N, et al. Clonal Abundance of Tumor-Specific CD4(+) T Cells Potentiates Efficacy and Alters Susceptibility to Exhaustion. Immunity. 2016;44(1):179-193.

22. Klebanoff CA, et al. Central memory self/tumor-reactive CD8+ T cells confer superior antitumor immunity compared with effector memory T cells. Proc Natl Acad Sci USA. 2005;102(27):9571-9576.

23. Gattinoni L, et al. Wnt signaling arrests effector T cell differentiation and generates CD $8+$ memory stem cells. Nat Med. 2009;15(7):808-813.

24. Gattinoni L, Klebanoff CA, Restifo NP. Paths to stemness: building the ultimate antitumour T cell. Nat Rev Cancer. 2012;12(10):671-684.

25. Wang $X$, et al. Phenotypic and functional attributes of lentivirus-modified CD19-specific human CD8+ central memory T cells manufactured at clinical scale. J Immunother. 2012;35(9):689-701. 
26. Wang X, Berger C, Wong CW, Forman SJ, Riddell SR, Jensen MC. Engraftment of human central memory-derived effector CD8+ T cells in immunodeficient mice. Blood. 2011;117(6):1888-1898.

27. Berger C, Jensen MC, Lansdorp PM, Gough M, Elliott C, Riddell SR. Adoptive transfer of effector CD8+ T cells derived from central memory cells establishes persistent T cell memory in primates. J Clin Invest. 2008;118(1):294-305.

28. Quezada SA, et al. Tumor-reactive CD4(+) T cells develop cytotoxic activity and eradicate large established melanoma after transfer into lymphopenic hosts. J Exp Med. 2010;207(3):637-650.

29. Xie Y, et al. Naive tumor-specific CD4(+) T cells differentiated in vivo eradicate established melanoma. J Exp Med. 2010;207(3):651-667.

30. Corthay A, et al. Primary antitumor immune response mediated by CD4+ T cells. Immunity. 2005;22(3):371-383.

31. Perez-Diez A, et al. CD4 cells can be more efficient at tumor rejection than CD8 cells. Blood. 2007;109(12):5346-5354

32. Linnemann $\mathrm{C}$, et al. High-throughput epitope discovery reveals frequent recognition of neo-antigens by CD4+ T cells in human melanoma. Nat Med. 2015;21(1):81-85.

33. Tran E, et al. Cancer immunotherapy based on mutation-specific CD4+ T cells in a patient with epithelial cancer. Science. 2014;344(6184):641-645.

34. Adusumilli PS, et al. Regional delivery of mesothelin-targeted CAR T cell therapy generates potent and long-lasting CD4-dependent tumor immunity. Sci Transl Med. 2014;6(261):261ra151.

35. Sommermeyer D, et al. Chimeric antigen receptor-modified T cells derived from defined CD8+ and CD4+ subsets confer superior antitumor reactivity in vivo. Leukemia. 2016;30(2):492-500.

36. Yang Y, et al. TCR engagement negatively affects CD8 but not CD4 CAR T cell expansion and leukemic clearance. Sci Transl Med. 2017;9(417):eaag1209.

37. Turtle CJ, et al. Immunotherapy of non-Hodgkin's lymphoma with a defined ratio of CD8+ and CD4+ CD19-specific chimeric antigen receptor-modified T cells. Sci Transl Med. 2016;8(355):355ra116.

38. Turtle CJ, et al. CD19 CAR-T cells of defined CD4+:CD8+ composition in adult B cell ALL patients. J Clin Invest. 2016;126(6):2123-2138.

39. Guedan S, et al. ICOS-based chimeric antigen receptors program bipolar TH17/TH1 cells. Blood. 2014;124(7):1070-1080.

40. Muranski P, et al. Tumor-specific Th17-polarized cells eradicate large established melanoma. Blood. 2008;112(2):362-373.

41. Fortier AH, Nacy CA, Sitkovsky MV. Similar molecular requirements for antigen receptor-triggered secretion of interferon and granule enzymes by cytolytic T lymphocytes. Cell Immunol. 1989;124(1):64-76.

42. Cherkassky L, et al. Human CAR T cells with cell-intrinsic PD-1 checkpoint blockade resist tumor-mediated inhibition. J Clin Invest. 2016;126(8):3130-3144.

43. Long AH, et al. 4-1BB costimulation ameliorates $\mathrm{T}$ cell exhaustion induced by tonic signaling of chimeric antigen receptors. Nat Med. 2015;21(6):581-590.

44. Farber DL, Yudanin NA, Restifo NP. Human memory T cells: generation, compartmentalization and homeostasis. Nat Rev Immunol. 2014;14(1):24-35.

45. Anderson AC, Joller N, Kuchroo VK. Lag-3, Tim-3, and TIGIT: Co-inhibitory Receptors with Specialized Functions in Immune Regulation. Immunity. 2016;44(5):989-1004.

46. Simon S, Labarriere N. PD-1 expression on tumor-specific T cells: Friend or foe for immunotherapy? Oncoimmunology 2017;7(1):e1364828

47. Eyquem J, et al. Targeting a CAR to the TRAC locus with CRISPR/Cas9 enhances tumour rejection. Nature. 2017;543(7643):113-117.

48. Crawford A, et al. Molecular and transcriptional basis of $\mathrm{CD} 4^{+} \mathrm{T}$ cell dysfunction during chronic infection. Immunity. 2014;40(2):289-302.

49. Brown DM. Cytolytic CD4 cells: Direct mediators in infectious disease and malignancy. Cell Immunol. 2010;262(2):89-95.

50. Zajac AJ, et al. Viral immune evasion due to persistence of activated T cells without effector function. J Exp Med. 1998;188(12):2205-2213.

51. Tatsumi T, et al. MAGE-6 encodes HLA-DRbeta ${ }^{*} 0401$-presented epitopes recognized by CD4+ T cells from patients with melanoma or renal cell carcinoma. Clin Cancer Res. 2003;9(3):947-954.

52. Altomonte M, Fonsatti E, Visintin A, Maio M. Targeted therapy of solid malignancies via HLA class II antigens: a new biotherapeutic approach? Oncogene. 2003;22(42):6564-6569.

53. Gay D, et al. Functional interaction between human T-cell protein CD4 and the major histocompatibility complex HLA-DR antigen. Nature. 1987;328(6131):626-629.

54. Engels B, Chervin AS, Sant AJ, Kranz DM, Schreiber H. Long-term persistence of CD4(+) but rapid disappearance of CD8(+) T cells expressing an MHC class I-restricted TCR of nanomolar affinity. Mol Ther. 2012;20(3):652-660.

55. Gattinoni L, et al. Acquisition of full effector function in vitro paradoxically impairs the in vivo antitumor efficacy of adoptively transferred CD8+ T cells. J Clin Invest. 2005;115(6):1616-1626.

56. Zhao Y, et al. High-affinity TCRs generated by phage display provide CD4+ T cells with the ability to recognize and kill tumor cell lines. J Immunol. 2007;179(9):5845-5854

57. Lupardus PJ, Birnbaum ME, Garcia KC. Molecular basis for shared cytokine recognition revealed in the structure of an unusually high affinity complex between IL-13 and IL-13Ralpha2. Structure. 2010;18(3):332-342.

58. Spangler JB, Moraga I, Mendoza JL, Garcia KC. Insights into cytokine-receptor interactions from cytokine engineering. Annu Rev Immunol. 2015;33:139-167.

59. Rizzuto GA, et al. Self-antigen-specific CD8+ T cell precursor frequency determines the quality of the antitumor immune response. JExp Med. 2009;206(4):849-866.

60. Teschner D, et al. Depletion of naive T cells using clinical grade magnetic CD45RA beads: a new approach for GVHD prophylaxis. Bone Marrow Transplant. 2014;49(1):138-144.

61. Touzot F, et al. CD45RA depletion in HLA-mismatched allogeneic hematopoietic stem cell transplantation for primary combined immunodeficiency: A preliminary study. J Allergy Clin Immunol. 2015;135(5):1303-9.e1.

62. Betz UA, Müller W. Regulated expression of gp130 and IL-6 receptor alpha chain in T cell maturation and activation. Int Immunol. 
1998;10(8):1175-1184.

63. Yi JS, Ingram JT, Zajac AJ. IL-21 deficiency influences CD8 T cell quality and recall responses following an acute viral infection. J Immunol. 2010;185(8):4835-4845.

64. Sugimura R, et al. Noncanonical Wnt signaling maintains hematopoietic stem cells in the niche. Cell. 2012;150(2):351-365.

65. Reya T, Clevers H. Wnt signalling in stem cells and cancer. Nature. 2005;434(7035):843-850.

66. Gattinoni L, Ji Y, Restifo NP. Wnt/beta-catenin signaling in T-cell immunity and cancer immunotherapy. Clin Cancer Res. 2010;16(19):4695-4701

67. Matloubian M, Concepcion RJ, Ahmed R. CD4+ T cells are required to sustain CD8+ cytotoxic T-cell responses during chronic viral infection. J Virol. 1994;68(12):8056-8063.

68. Spitzer MH, et al. Systemic Immunity Is Required for Effective Cancer Immunotherapy. Cell. 2017;168(3):487-502.e15.

69. Rakhra K, et al. CD4(+) T cells contribute to the remodeling of the microenvironment required for sustained tumor regression upon oncogene inactivation. Cancer Cell. 2010;18(5):485-498.

70. Jonnalagadda $\mathrm{M}$, et al. Chimeric antigen receptors with mutated IgG4 Fc spacer avoid fc receptor binding and improve $\mathrm{T}$ cell persistence and antitumor efficacy. Mol Ther. 2015;23(4):757-768.

71. Kim D, Pertea G, Trapnell C, Pimentel H, Kelley R, Salzberg SL. TopHat2: accurate alignment of transcriptomes in the presence of insertions, deletions and gene fusions. Genome Biol. 2013;14(4):R36.

72. Anders S, Pyl PT, Huber W. HTSeq--a Python framework to work with high-throughput sequencing data. Bioinformatics. 2015;31(2):166-169.

73. Love MI, Huber W, Anders S. Moderated estimation of fold change and dispersion for RNA-seq data with DESeq2. Genome Biol. 2014;15(12):550. 